\title{
Approaches combining methods of operational research with Business Process Model and Notation - a systematic review
}

\author{
Hana Tomaskova ${ }^{\text {Corresp., } 1}$, Gerhard-Wilhelm Weber ${ }^{2,3}$ \\ 1 University of Hradec Kralove, Faculty of Informatics and Management, Hradec Kralove, Czech Republic \\ 2 Faculty of Engineering Management, Poznan University of Technology, Poznan, Poland \\ 3 Institute of Applied Mathematics, Middle East Technical University, Ankara, Turkey \\ Corresponding Author: Hana Tomaskova \\ Email address: hana.tomaskova@uhk.cz
}

Background: Business process modelling is increasingly used not only by the companies' management but also by scientists dealing with process models. Process modeling is seldom done without decisionmaking nodes, which is why operational research methods are increasingly included in the process analyses.

Objective: This systematic literature review aimed to provide a detailed and comprehensive description of the relevant aspects of used operational research techniques in Business Process Model and Notation (BPMN) models.

Methods: Web Of Science of Clarivate Analytics was searched for 128 studies of that used operation research techniques and business process model and notation, published in English between 1 January 2004 and 18 May 2020. The inclusion criteria were as follows: Use of Operational Research methods in conjunction with the Business process model and notation, and is available in full-text format. Papers were not excluded based on methodological quality. The background information of the included studies, as well as specific information on the used approaches, were extracted.

Results: In this research, thirty-six studies were included and considered. Eleven specific methods falling into the field of Operations Research have been identified, and their use in connection with the process model was described.

Conclusion: Operational research methods are a useful complement to BPMN process analysis. It serves not only to analyze the probability of the process, its economic and personnel demands but also for process reengineering. 


\title{
Approaches combining operation research methods with Business Process Model and Notation - a systematic review
}

\author{
${ }_{4}$ Hana Tomaskova ${ }^{1}$ and Gerhard-Wilhelm Weber ${ }^{2,3}$ \\ ${ }_{5}^{1}$ University of Hradec Kralove, Faculty of Informatics and Management, Hradec Kralove, \\ Czech Republic \\ ${ }^{2}$ Faculty of Engineering Management, Poznan University of Technology, ul. Strzelecka \\ 11, 60-965 Poznan, Poland \\ ${ }^{3}$ Institute of Applied Mathematics, Middle East Technical University, Ankara, Turkey \\ Corresponding author: \\ Hana Tomaskova ${ }^{1}$ \\ Email address: hana.tomaskova@uhk.cz
}

13 ABSTRACT

Background: The business processes modelling has long ceased to belong only to the area of company management. This process analysis approach is currently being spread to all possible domains. However, business processes cannot exist without decision-making and unifying conditions, barriers or delays, so this is the reason why it is necessary to focus on the methods of operational research as a means of managing and optimizing the flow of process tokens when analyzing business processes.

Objective: This systematic literature review aimed to provide a detailed and comprehensive description of the relevant aspects of used operational research techniques in Business Process Model and Notation (BPMN) models and present results of bibliometric analysis of found documents. We focused on the analysis of authors, keywords, year of publication, research areas, citations and more. We also analyzed the potential effect of the upgrading of the notations.

Methods: The Web Of Science (WOS) database of Clarivate Analytics was searched for 128 studies that used operation research techniques and Business Process Model and Notation (BPMN), and that was published in English between January 1, 2004, and May 18, 2020. The inclusion criteria were as follows: Use of Operational Research methods in conjunction with the Business process model and notation, and is available in full-text format. Papers were not excluded based on methodological quality. The background information of the included studies, as well as specific information on the used approaches, were extracted.

Results: In this research, thirty-six studies were included and considered. Eleven specific methods falling into the field of Operational Research have been identified, and their use in connection with the process model was described.

Conclusion: Operational research methods are a useful complement to BPMN process analysis. It serves not only to analyze the probability of the process, its economic and personnel demands but also for process reengineering.

\section{INTRODUCTION}

It has been more than 15 years since "Business Process Model and Notation" or "Business Process Modelling Notation" (BPMN) is officially a notation for process modelling. During its lifetime, this notation has gained many users and, thanks to its user-friendliness, is used in many areas. It is this expansion that has led to the interconnection and use of other technologies and methods. The fundamental problem of any complex process is decision making. Operational research as a popular scientific approach is so often associated with procedural issues, and its connection to BPMN is more than natural. This article focuses on the analysis of the relationship between the Business Process Model and Notation (BPMN) process modelling and specific methods of operational research.

BPMN was created by the Business Process Management Initiative (BPMI) as an open standard. The 
BPMN has very much similarity to flowcharts or Petri net but offers much more sophisticated tools to describe and simulate behaviour. Silver (2009) said that this approach is an "event-triggered behaviour," a description of the "something happened" mode. Business Process Modelling is used to describe, recognize, re-engineer, or improve processes or practices, Tomaskova (2017). Business Process Model and Notation (BPMN) is the language that is used to model business process steps from start to end. The notation has been explicitly designed for wide-ranging use in process analysis, OMG - The Object Management Group (2011). BPMN is both intelligible to non-specialists but at the same time notation allows a complicated process to be represented between different participants. Another, very significant feature of BPMN is its "business-friendly" orientation. This orientation and processes modelling is essential for the company's business and knowledge.

Operational Research (OR) is concerned with formulating, modelling, and solving a variety of decision-making situations in which we try to find optimal or select the best of the acceptable solutions. The company's philosophy and decide over business data are the most crucial management actions. The task of the manager is to select in the real system the problem to be analyzed and to formulate it precisely. The standard way is the expression of the economic model and then the formulation of a mathematical model. It is necessary to build a simplified model of the real financial system, which will include only the essential elements that describe the formulated problem. The manager has to set the goal of the analysis and subsequent optimization. Important is to define all operational or processes that influence this goal, to describe all the factors, and to express the relations between the stated purpose and the mentioned processes and factors verbally.

The paper is divided into the following parts. The "Related works and background" section lists research articles that are relevant to a given combination of BPMN and OR areas. That part briefly provides essential information on the approaches that are fundamental to this systematic review. The "Research methodology" section describes a systematic search, i.e. entry conditions, exclusion criteria and limitations. The "Results" section presents the results of the analysis of articles fulfilling the requirements of the systematic review. we analyzed publications through conditions of the publication time, their citations, scientific areas, the cooperation of authors and keywords. Subsequently, we examined selected articles in terms of methodology, approach and research areas. In the "Discussion", we focus on scientific gaps and future research. We present a research area where we expect an increase in publications, including their specific components. We also discuss the future development of applied methods and approaches. Finally, the "Conclusion" section summarizes the results and benefits of this study.

\section{RELATED WORKS AND BACKGROUND}

Background information and related works are listed in the paragraphs below. We first focus on process modelling and BPMN and then Operational Research and its essential methods and approaches.

Organizational processes and decision support can be captured in many ways, and for many areas, we can mention, for example : strategic management by: Maltz and Kohli (1996); Certo (2003); Tomaskova (2009); Maresova (2010); Tsakalidis et al. (2019); product development research and innovation implementation, see Repenning (2002); Garcia (2005); IT and economic analyzes see Shane and Cable (2002); Dedrick et al. (2003); Krenek et al. (2014); Tomaskova et al. (2015); Maresova et al. (2016); Tomaskova et al. (2016); Maresova et al. (2017); Cheng et al. (2019); Tomaskova et al. (2019a,b); Kopecky and Tomaskova (2019, 2020); different simulation approaches analysis, see Sterman (1994); Kozlowski et al. (2013); Cimler et al. (2018) or non-standard optimization techniques by: Gavalec and Tomaskova (2010); Bacovsky et al. (2013); Tomaskova and Gavalec (2013, 2014); Gavalec et al. (2014, 2015); Cimler et al. (2017); Oudah et al. (2018).

Some of the authors try to provide a solution for process model analysis. For example, Melao and Pidd (2000) discussed the strengths and limitations of the various modelling approaches used in business process transformation. The paper by Glassey (2008) compares three process modelling processes used in case studies. The article by Sadiq and Orlowska (2000) analyze process models using graph reduction techniques. Other authors like van der Aalst et al. (2007); Krogstie et al. (2006) use specific tools, frameworks, and methods for process analysis and modelling.

\section{Business process modelling}

Process modelling and Business process management (BPM) has a significant impact today. Process modelling is currently mainly a graphical representation of processes, i.e. in what order particular 
activities should be implemented and what inputs and outputs processes require for proper functioning. The primary goal of process modelling is to increase the efficiency and effectiveness of the entire process as well as partial activities. Many business process modelling techniques have been proposed over the last decades, so the paper Recker et al. (2009) comparatively assesses representational analyses of 12 popular process modelling techniques to provide insights into the extent to which they differ from each other. The review business process modelling literature and describe the leading process modelling techniques falling to and before 2004 are published in the paper Aguilar-Saven (2004). The topic of visualization of business process models was investigated in publication Dani et al. (2019), where authors performed a systematic literature review in the topic "visualization of business process models". A fascinating article is the publication Kalogirou (2003), which illustrate how AI techniques might play an essential role in the modelling and prediction of the performance and control of the combustion process. Although initially, BPM focused mainly on the industrial, service and business sectors, it has also appeared in other sectors in recent years. The popularity of BPMN is confirmed, for example, by the article by authors Zarour et al. (2019), where the current state of the art of BPMN extensions is presented. Publication De Ramon Fernandez et al. (2019) deals with the optimization of clinical processes.

\section{Business Process Model and Notation}

BPMN is a language for creating business process models Silver (2009). Under the auspices of the Object Management Group (OMG), the Business Process Management Initiative (BPMI) created the BPMN as an open standard in 2004 by the first version 1.0. In 2005, BPMI merged with the Object Management Group (OMG). The following year, OMG issued the BPMN specification document. In 2010, BPMN version 2.0 was developed, and the current version of BPMN 2.0.2 was released in December 2013. History of BPMN and notation development is a frequent topic of BPMN publications, we can mention Nisler and Tomaskova (2017); Kocbek et al. (2015); Chinosi and Trombetta (2012); White (2008); Van der Aalst et al. (2012); Recker (2012). BPMN is similar to flowcharts and is based on the concept of Petri nets, but it is a more sophisticated and user-friendly language. The graphic form of BPMN makes it understandable even for non-experts. In BPMN, we distinguish several types of elements that we can use in modelling. The specific standards link these elements. In the base classification, we define four groups of items. These are Flow Objects, Connecting Objects, Swimlanes, and Artifacts, see OMG - The Object Management Group (2011).

\section{Operational Reserach}

Operational research (OR) is the well-known approach of applying analytical and advanced methods to help make the best possible decisions. As early as 1980, Article by authors Shannon et al. (1980) presented the results of a survey of the perception of usefulness and knowledge of the twelve OR methodologies commonly used in the practice of industrial engineering. The article by Dubey (2010) defines the relation between OR and another branch of sciences. The paper Gu et al. (2010) presents a detailed survey of the research on warehouse design, performance evaluation, practical case studies, and computational support tools. The paper Negahban and Smith (2014) provides a review of discrete event simulation publications with a particular focus on applications in manufacturing.

Operational research methods are often associated with new technologies. In paper Sarac et al. (2010), a state-of-the-art on RFID technology deployments in supply chains is given to analyze the impact on the supply chain performance. Xu et al. (2011), in their paper, tries to identify future trends of computer-aided process planning (CAPP). Dynamic ride-share systems is investigated in the paper Agatz et al. (2012).

\section{Linear programming}

One of the most popular areas of operational research in practice is linear programming (LP). The mathematical model of linear programming tasks contains a single linear purpose function, and the actual constraints of the problem are described only by linear equations and inequalities. In economic practice, these tasks are most often encountered. Linear programming is very well described in books: Dantzig (1998); Schrijver (1998); Dorfman et al. (1987)

\section{Multicriterial decision making}

The solving of multi-criteria decision-making (MCDM) tasks comprise the look for optimal values of the unknowns, which are simultaneously assessed according to several often contradictory criteria. Thus, the mathematical model of multi-criteria decision problems contains several purpose functions. 
Depending on how the sets of decision variants are defined, we are talking about the tasks of multicriteria linear programming or multi-criteria evaluation of options. A review of applications of Analytic Hierarchy Process in operational management is inverstigated in Subramanian and Ramanathan (2012). The paper Velasquez and Hester (2013) performs a literature review of common Multi-Criteria Decision Making methods. The authors present the results of a bibliometric-based survey on AHP and TOPSIS techniques in publication Zyoud and Fuchs-Hanusch (2017).

\section{Project planning}

Tasks of project management, consist of several separate activities that are interdependent and may be run simultaneously. The most used method is the so-called network analysis, where a network graph is created from the left chronologically arranged project activities representing the project life cycle. The longest possible path from the beginning to the end of the project is recorded by "the critical path". The non-observance of this path will lead to a slowing down of the whole project, whose time duration is to be optimized. The optimistic, pessimistic, and most probable estimate of the implementation of the entire project is determined. The paper Nutt (1983) relates the project planning process and implementation. Critical Path Method (CPM) is found in the paper Jaafari (1984), to be equally useful as a planning tool for linear or repetitive projects.

The Resource-Constrained Project Scheduling Problem (RCPSP) is a general problem in scheduling. The paper Pellerin et al. (2020) examines the general tendency of moving from pure metaheuristic methods to solving the RCPSP to hybrid methods that rely on different metaheuristic strategies.

Cimr et al. (2018)

\section{Nonlinear programming}

Non-Linear programming is the case when the purpose function is not linear. Tasks then often have a large number of local extremes and often also have great difficulty finding them.

\section{Dynamic programming}

If constraints are functions of some parameter, which is most often time, we are talking about dynamic programming. This approach deals with the modelling of more complex multi-stage optimization problems divisible into related sub-problems. Depending on the time parameter, the system is always in one of the acceptable states during the process. At certain times it is necessary to choose from a set of possible decisions, which again results in the transition to the next state. We call the strategy a sequence of these states of the system and choices, looking for the course with the best valuation. Simulations are often used to model and analyze the operation of complex systems without realization and in less than real-time.

- Queuing theory is a type of dynamic programming task. It deals with streamlining the functioning of systems in which it is necessary to gradually serve all units whose requirements are continuously met on so-called service lines. The challenge is to find the most effective way to handle these requirements.

- Inventory management models address the issue of optimizing the supply process and the volume of inventory stored. Costs associated with ordering, issuing, and keeping stocks in stock should be minimized.

\section{Stochastic programming}

Stochastic programming deals with optimization problems in which they act as parameters of their constraints of random variables. Probabilistic calculus methods solve these problems, and their results have the character of random variables. Stochastic processes can also be ranked among tasks with the uncertainty of input data. This approach is used to describe the behavior of systems evolving. We are talking about stochastic processes, a special case is the so-called Markov chains and Markov processes. Basic books on this topic are, for example:Kall et al. (1994); Birge and Louveaux (2011); Shapiro et al. (2014).

\section{RESEARCH METHODOLOGY}

Kitchenham and Charters (2007) highlighted three essential elements for systematic literary review. It is the determination of research question(s), the organisation of an unbiased and extensive analysis of related publications, and the determination of precise criteria of inclusion and exclusion.

We identified three research questions: 
- Research question 1 (R1): Greater adaptability of BPMN elements causes higher application of this notation in publications.

- Research question 2 (R2): The connection between BPMN and OR methods is most often applied to the business and economic area.

- Research question 3 (R3): The queue theory is the most widely used method in BPMN processes.

The analysis process and criteria are given in the following relevant subsections.

\section{Eligibility criteria}

The main features of the study are publications listed in the database Web Of Science (WOS) of Clarivate Analytics, published between January 1, 2004, and May 18, 2020, and containing the search strings. The year 2004 was selected as the starting time point as it was the BPMN created by the Business Process Management Initiative (BPMI).

Exclusion criteria (EC) are:

- $\mathrm{EC} 1=$ The publication is published in a language other than English.

- $\mathrm{EC} 2=$ The publication is not available as full text.

- EC3= The publication does not coincide with the topic of systematic research.

- $\mathrm{EC} 4=\mathrm{BPMN}$ is used only as a presentation tool and not as part of the research.

\section{Information sources and Search}

The primary source of information for the study is the database Web Of Science (WOS) of Clarivate Analytics. An advanced search was performed for the search query mentiones below. The search was performed in the Topics (TS) section.

Especially, the CORE database with the indexes listed in Table 1 was selected. The search was performed for "All document types", "All languages" and the years 2004 - 2020.

\begin{tabular}{l|l} 
Indexes & Abbreviation \\
\hline Science Citation Index Expanded & ( SCI-EXPANDED) \\
Social Sciences Citation Index & ( SSCI) \\
Arts \& Humanities Citation Index & ( A\&HCI) \\
Conference Proceedings Citation Index- Science & ( CPCI-S) \\
Conference Proceedings Citation Index- Social Science \& Humanities & ( CPCI-SSH) \\
Book Citation Index- Science & ( BKCI-S) \\
Book Citation Index- Social Sciences \& Humanities & ( BKCI-SSH) \\
Emerging Sources Citation Index & ( ESCI) \\
Current Chemical Reactions & ( CCR-EXPANDED) \\
Index Chemicus & ( IC)
\end{tabular}

Table 1. Web of Science Core Collection Indexes

\section{Study selection}

The first step of the review process involved title and abstract screening, followed by a full-text review for articles that were not definitively excluded after the title and abstract screening. Two independent assessors verified the title and abstract screening and also full-text review. One assessed the suitability of the result from the perspective of Operation research and second assessed the study from the IT perspective, i.e., whether it is a BPMN notation and its use. Articles were included if they met all the following criteria: (i) Using the method of operational research ; (ii) a BPMN model was used and (iii) available in English and complete full-text format (i.e., abstracts, commentaries, letters, and unpublished data were excluded). Studies were not excluded based on methodological quality.

In this study, selected publications were examined from many perspectives, and each contribution was coded according to different criteria. This study aims to enhance the discipline's fundamental progress in 
understanding the linkage of operational research methods with BPMN. The results of this study could encourage scientists to use operational research methods for process analysis.

The limitation of this review is restricting the review to English-language publications of process analysis using OR and BPMN published from January 1, 2004, to May 18, 2020. This restriction may have omitted some relevant studies in other languages or published after May 18, 2020.

\section{Data collection process}

Data was collected based on keywords selected from the article Lane et al. (1993), which analyzed the quantitative techniques of Operation Research. From this document, the 18 Operation Research methods were selected and listed in the table 2 .

\begin{tabular}{l|c} 
Query & Results \\
\hline TS=( Computer AND programming AND BPMN $)$ & 6 \\
TS=( Decision AND Analysis AND BPMN $)$ & 40 \\
TS=( Decision AND theory AND BPMN) & 7 \\
TS=( Dynamic AND programming AND BPMN) & 4 \\
TS=( Heuristic AND programming AND BPMN $)$ & 0 \\
TS=( Hypothesis AND testing AND BPMN) & 2 \\
TS=( Inventory AND control AND BPMN $)$ & 1 \\
TS=( Linear AND regression AND BPMN) & 2 \\
TS=( Linear AND programming AND BPMN $)$ & 3 \\
TS=( Math AND analysis AND BPMN) & 0 \\
TS=( Math AND programming AND BPMN $)$ & 0 \\
TS=( Network AND analysis AND BPMN) & 23 \\
TS=( Nonlinear AND programming AND BPMN $)$ & 0 \\
TS=( PERT AND BPMN) & 0 \\
TS=( Probability AND BPMN) & 14 \\
TS=( Queuing AND BPMN) & 9 \\
TS=( Statistic AND BPMN) & 2 \\
TS=( Stochastic AND processes AND BPMN $)$ & 15
\end{tabular}

Table 2. Electronic search strategy in WoS

The articles found based on these keywords with BPMN intersection were further categorized as to whether they correspond to the given keywords and their meaning. The main results of the systematic literature review were obtained by analyzing by the two main guidelines of PRISMA : Moher et al. (2009) and MECIR : Higgins et al. (2018).

\section{Synthesis of results}

First, the individual studies were subjected to bibliometric analysis and then the studies were assessed according to the content and used methods. The bibliometric analysis describes and analyses up to date research. It aims at summarizing the latest progress in the field by quantitatively investigating the literature. This method provides a vast canvas of knowledge from the micro-level (institutes, researchers, and campuses) to the macro-level (countries and continents) Mryglod et al. (2013).Frequency analysis is used to find the most frequented scientific areas, the most publishing countries, the most common keywords. Science mapping is performed using the VOS viewer, Venn diagram, bar or bubble graph, Van Eck et al. (2010); Cobo et al. (2011).

The Venn/Euler diagram graphically represents the relationships of the most massive set of keywords. Euler diagrams are considered to be an effective means of visualizing containment, intersection, and exclusion. The goal of such graphs is to communicate scientific results visually. Leonhard Euler first popularized the principle of labeled closed curves in the paper Euler (1775) Alternative names for Euler diagrams include "Euler circles". They can also be incorrectly called Venn diagrams. Venn diagrams require all possible curve intersections to be present, so can be seen as a subset of Euler diagrams, that is, every Venn diagram is a Euler diagram, but not every Euler diagram is a Venn diagram. John Venn introduced Venn diagrams a hundred years after Euler in the paper Venn (1880). Venn diagram is a schematic graph used in logic theory to depict collections of sets and represent their relationships. 


\section{RESULTS}

The initial search resulted in 128 articles. After removing duplicates, 107 items underwent title and abstract screening, yielding 61 articles for full-text review. The final number of included papers for information abstraction was 36 . Overview of the number of publications according to exclusion criteria is shown in Figure 1.

Eighteen keywords selected from the paper by Lane et al. (1993) were involved in the study. These keywords have been classified according to whether a publication meeting a study condition has been found for them. Only for 13 keywords were found a publication suitable for this study, as can be seen in table 2

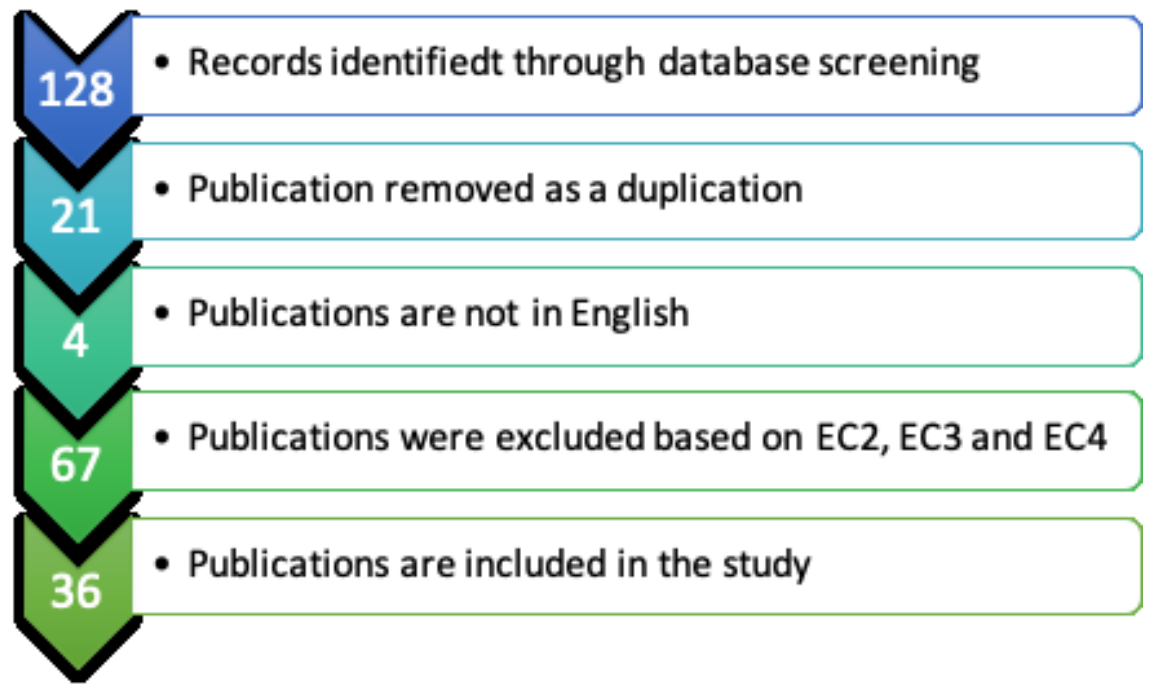

Figure 1. Overview of the systematic review

\section{Categorization of Publications Based on the Clarivate Analytics}

Journals and books covered by the Web of Science Core Collection are assigned to at least one Web of Science category. Each Web of Science category is mapped to one research area Clarivate Analytics (2019). Research areas for selected publications are:

- COMPUTER SCIENCE (CS)

- ENGINEERING (En)

- OPERATIONAL RESEARCH MANAGEMENT SCIENCE (OR)

- BUSINESS ECONOMICS (BE)

- ROBOTICS (Ro)

- AUTOMATION CONTROL SYSTEMS (ACS)

- TELECOMMUNICATIONS (Te)

- TRANSPORTATION (Tr)

We selected four main groups, for which we compiled a bar graph and a Venn diagram after analysis. We chose the number of four research areas for representation in the Venn diagram; four sets are still well arranged. Another argument was the number of publications in other areas, where the set "ROBOTICS" contains two documents and the sets "AUTOMATION CONTROL SYSTEMS", "TELECOMMUNICATIONS" and "TRANSPORTATION" each one document.

Bar graph on figure 2 is based on frequency analysis and contains the total number of publications in a given research area, their average number of citations, and the corresponding average number of pages per 
paper. The graph shows the results by type of purpose. The first part shows the frequencies of documents for research areas. The second part focuses on the average number of citations, and the third shows the average number of pages per article.

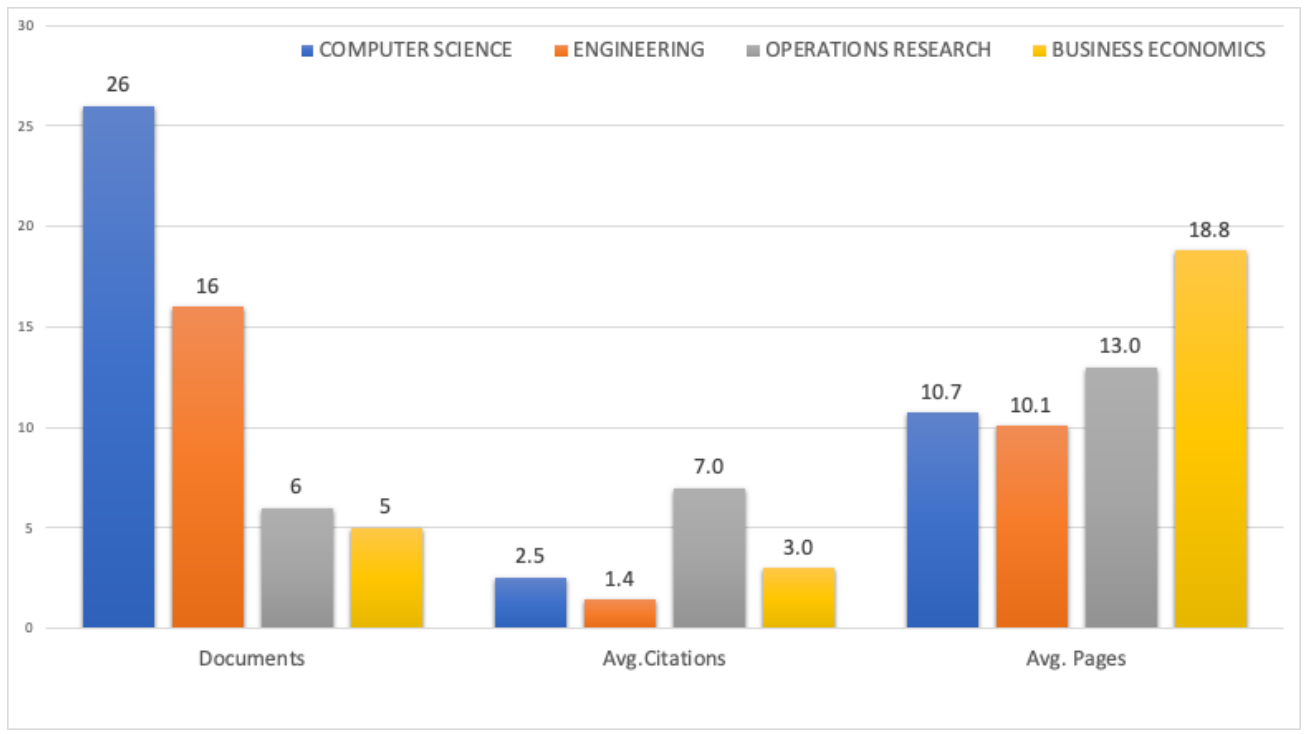

Figure 2. Research areas of selected publications; Documents, Average Citations and Average Pages

The Venn diagram, in figure 3, shows selected four research areas as sets, including their intersection areas. In a specific area, we also stated the relevant number of documents and their average number of citations.

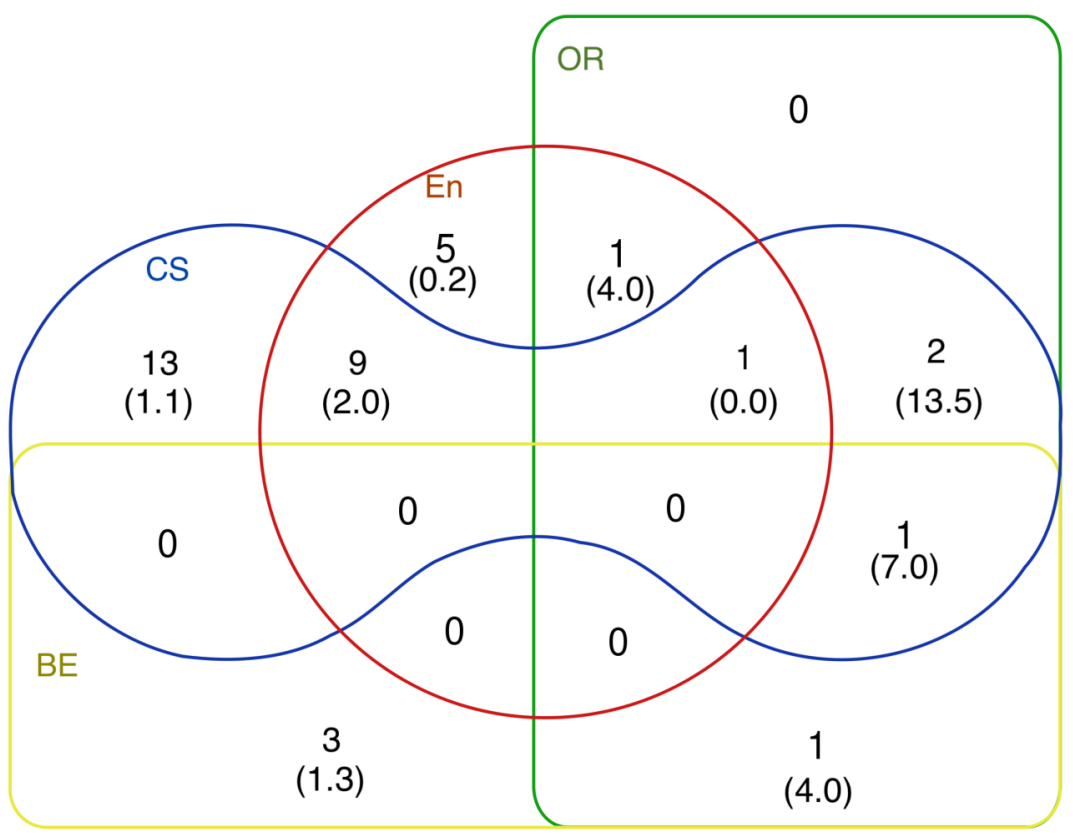

Figure 3. Venn diagram of research areas of selected publications; average citation is listed in the parentheses.

This part of the bibliometric analysis showed us the answer to the research question R2. Although BPMN was explicitly designed for corporate analysis and economic analysis, and Operational Research 
focuses primarily on addressing managerial decisions, most publications are not in the field of Business Economics. On the contrary, there are the fewest publications in the BE area. Most documents are in the field of Computer Science. Papers in the field of Operational Research received the most citations. The research area "BE" has the lead in the most extended publications, i.e. the number of average pages per paper.

Result1: Research question R2 - not confirmed.

\section{Year of Publication}

Figure 4 illustrates the distribution over time of the selected publications with BPMN milestones. The BPMN versions adoption dates, taken from OMG.org (2018), complements this figure.

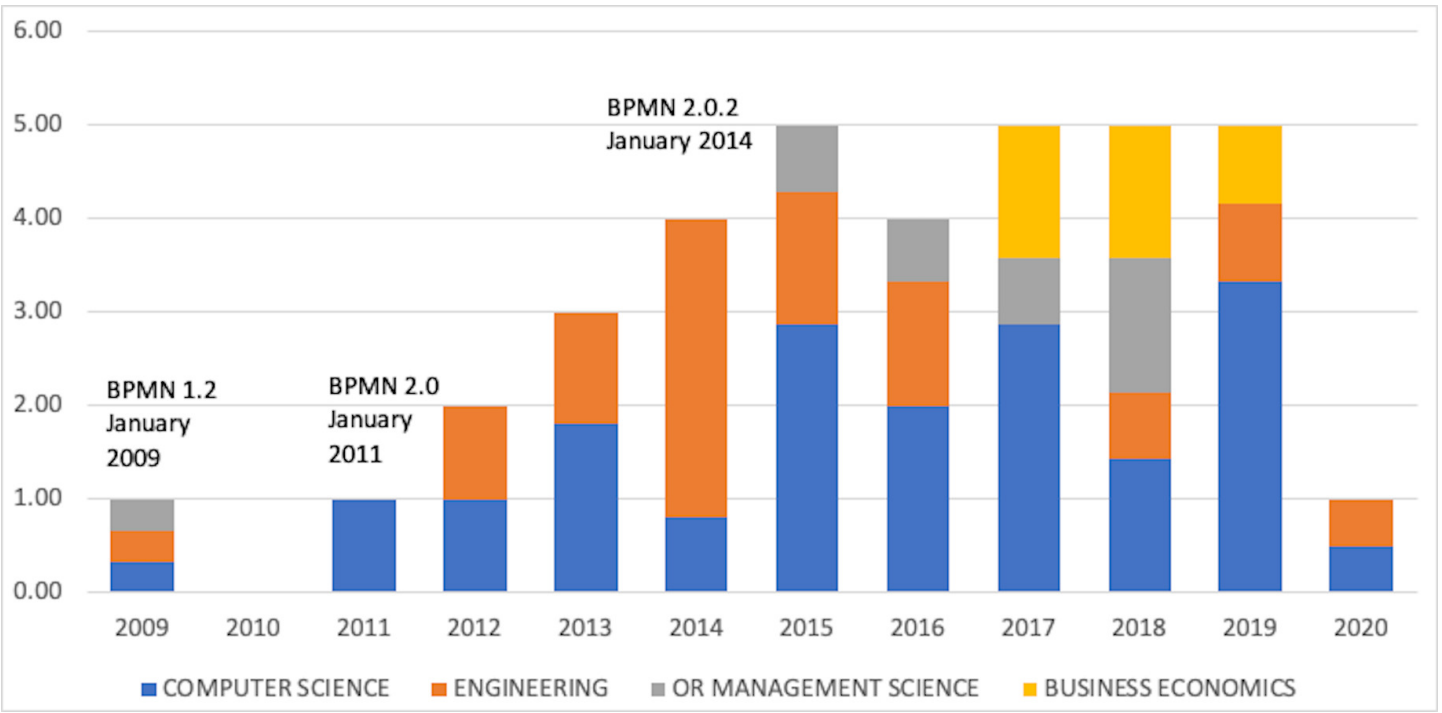

Figure 4. Distribution of the publications by year and their representation in research areas

BPMN versions brought more or fewer changes in notation. While the changes between BPMN 1.0 and BPMN 1.2 were rather cosmetic; for example, renaming "Rule" elements to "Conditional" or slight increasing the number of elements from 48 to 55. The arrival of BPMN 2.0 was a breakthrough. As of BPMN version 2.0, it is possible to create a new "Choreography model", "Collaborations model" and "Conversation model" in BPMN in addition to collaborative processes and internal (private) business processes. Events are now divided into "interrupted" and "non-interrupted" and "catching" and "throwing". The message type is newly introduced, and the data object has three specifications. BPMN 2.0 contains 116 elements. BPMN 2.0 represents the largest revision of BPMN since its inception. BPMN 2.0.2 included only minor modifications in terms of typos.

Given the magnitude of changes between versions of the BPMN notation, the sharp increase in publications following the introduction of the BPMN 2.0 notation can be considered a confirmation of research question R1. It is very interesting that only in 2017 will publications from the field of business economic appear for the first time.

Result: Research question R1 - confirmed.

The average number of citations of analyzed documents is 2.22 , where the 1 st quartile has a value of 0,3 quartile is 3.75 , Median is equal to one and data variability above the third quartile is limited to 7 citations. We identified two outliers values: 12 citations for Hasic et al. (2018) and 15 citations for paper Wu et al. (2015).

\section{Author analyses}

Bibliometric analysis cannot be done without review by the authors. We focused on illustrating coauthorship. The total number of authors of publications selected for this study is $84:$ al achhab, m (1), aouina, zk (1), ayani, r (1), aysolmaz, b (1), bahaweres, rb (1), batoulis, k (1), ben ayed, ne (1), ben said, 1 (1), ben-abdallah, h (3), bisogno, s (1), bocciarelli, p (1), boukadi, k (1), braghetto, kr (1), burattin, a (1), calabrese, a (1), ceballos, hg (2), chien, cf (1), cho, sy (1), creese, s (1), cunha, p (1), d'ambrogio, a (1), 
d'ambrogio, sa (1), de lara, j (1), de smedt, j (2), demirors, o (1), duran, f (2), el hichami, o (1), el mohajir, b (1), ferreira, je (1), figl, k (1), fitriyah, a (1), flores-solorio, v (2), fookes, c (1), garcia-vazquez, jp (1), ghiron, nl (1), ghlala, r (1), gomez-martinez, e (1), hansen, z (1), hansen, znl (3), happa, j (1), hasic, f (2), herbert, lt (8), holm, g (1), iren, d (1), jacobsen, p (3), jobczyk, k (1), kamrani, f (1), khlif, w (2), kluza, k (1), ligeza, a (1), manuel vara, j (1), marcos, e (1), mazhar, s (1), mendling, j (1), mendoza morales, le (1), mengersen, k (1), monsalve, c (1), moradi, f (1), naoum, m (1), onggo, bss (1), pablo garcia, j (1), perez-blanco, f (1), pitchforth, j (1), proudlove, nc (1), rekik, m (1), rocha, c (2), rosemann, m (1), rozy, nf (1), salaun, g (2), sharp, r (4), sperduti, a (1), suchenia, a (1), tang, rz (1), tokdemir, g (1), tomaskova, h (1), vanden broucke, sklm (1), vanthienen, j (3), veluscek, m (1), villavicencio, m (1), vincent, jm (1), weske, m (1), wisniewski, p (1), wu, ppy (2), xie, y (1).

These authors form more substantial or smaller groups, as can be seen in Figure 5. We grouped the authors according to their co-author's collaboration into groups where a curve connects the co-authors. The size of the node of this connection corresponds to the number of documents of the given author. The colour distinction of the authors was created using the average year of publication of the author's papers.

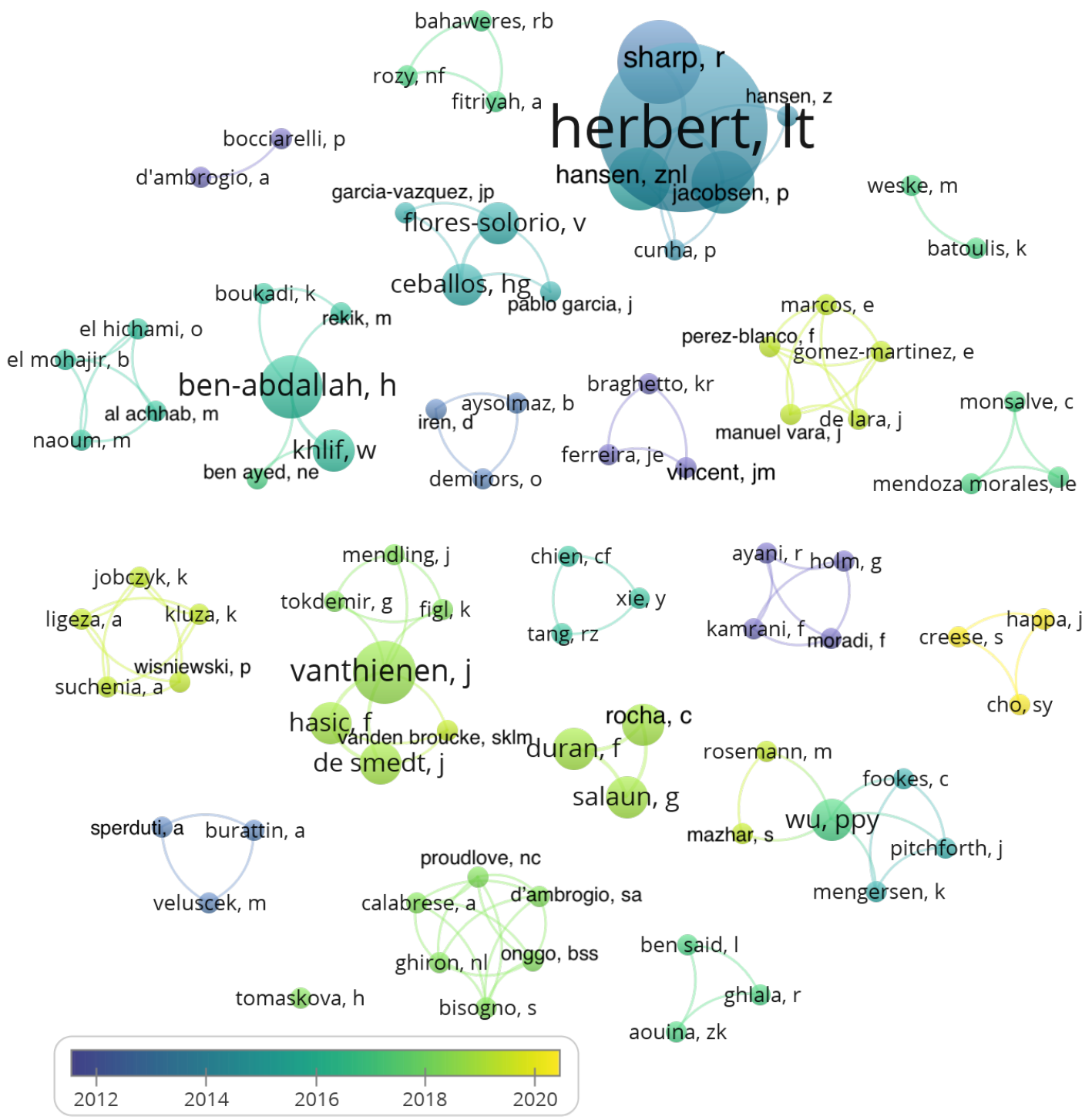

Figure 5. Division of authors into groups according to co-authorship.

For the average values of the author's publications year, we performed analyze showing that the 1st quartile corresponds to 2015, the third quartile 2018.5 and the median is 2017 . The variability outside the lower and upper quartiles is given by 2011 and 2020 . We identified one outlier value corresponding to the 
year 2009

The most prominent groups are around the authors listed in figure 6. This figure also contains the number of documents of the author, the total number of citations and their average value.

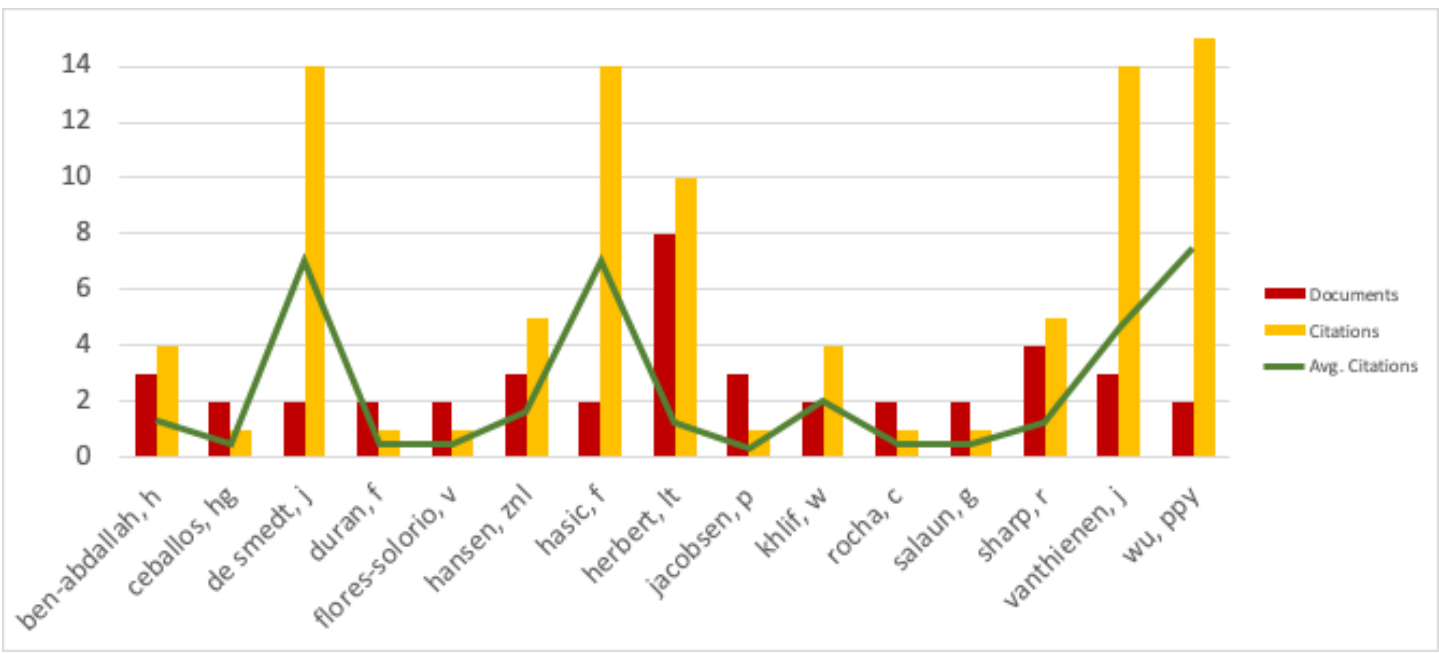

Figure 6. Fifteen most successful authors

From this authors analysis, we can highlight the authors $\mathrm{Wu}$, py, who have the highest average amount of citations (7.5), De Smedt, J. (7) and Hasic, F. (7); Herbert, L.T., who has the most documents (8) and Tomaskova, H., which has no co-author's connection.

The authors were also analyzed in terms of their affiliation to the country or region. A total of 25 countries were identified and their location, including the number of relevant publications, is shown in Figure 7. Most records are identified for Denmark (8), followed by Tunisia (4), three records are for Belgium, France, Saudi Arabia, Italy and Spain.

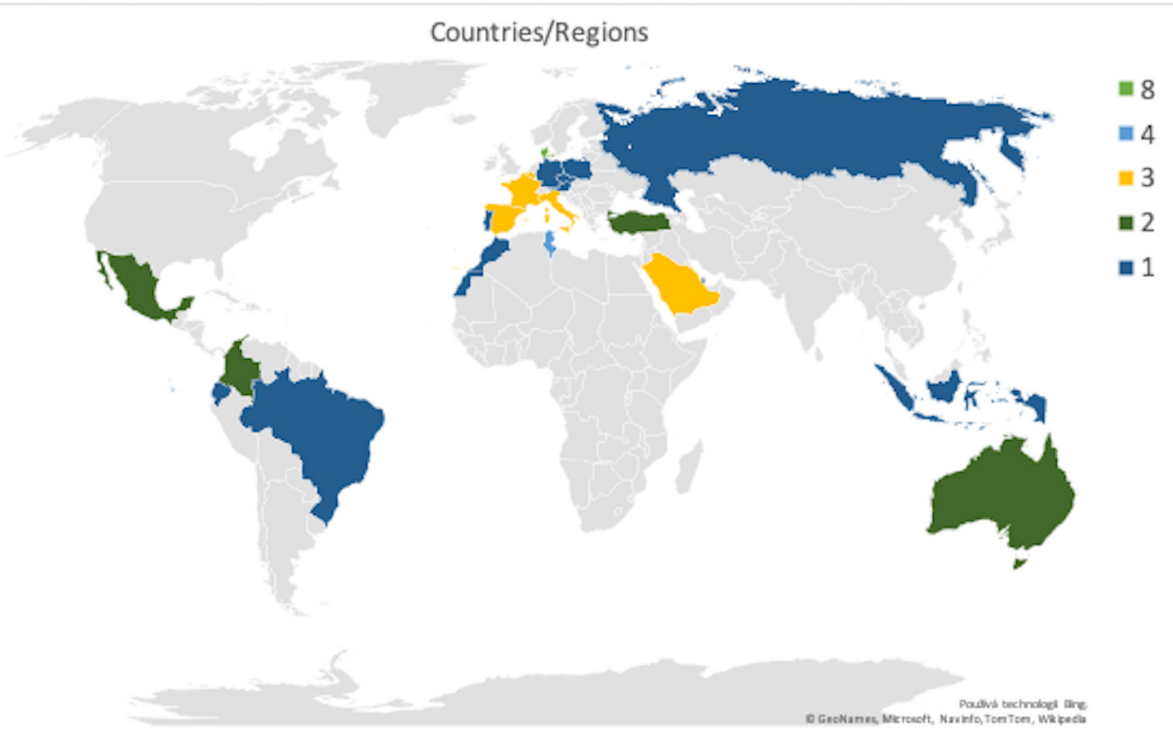

Figure 7. Location of publications in the world, own processing

\section{Keywords analysis}

The keywords were categorized according to the keywords identified by the published authors and the keywords PLUS assigned by Clarivate Analytics databases. The data in KeyWords Plus are words or phrases that frequently appear in the titles of an article's references but do not appear in the title of the 
item itself. Based upon a special algorithm that is unique to Clarivate Analytics databases, KeyWords Plus enhances the power of cited-reference searching by searching across disciplines for all the articles that have cited references in common, more information is on the web link Clarivate Analytics (2018). A total of 130 unique keywords and 46 unique keywords PLUS were found for selected publications.

A total of 130 author keywords are mentioned in the publications and a general view of their interconnection can be seen in Figure 8.

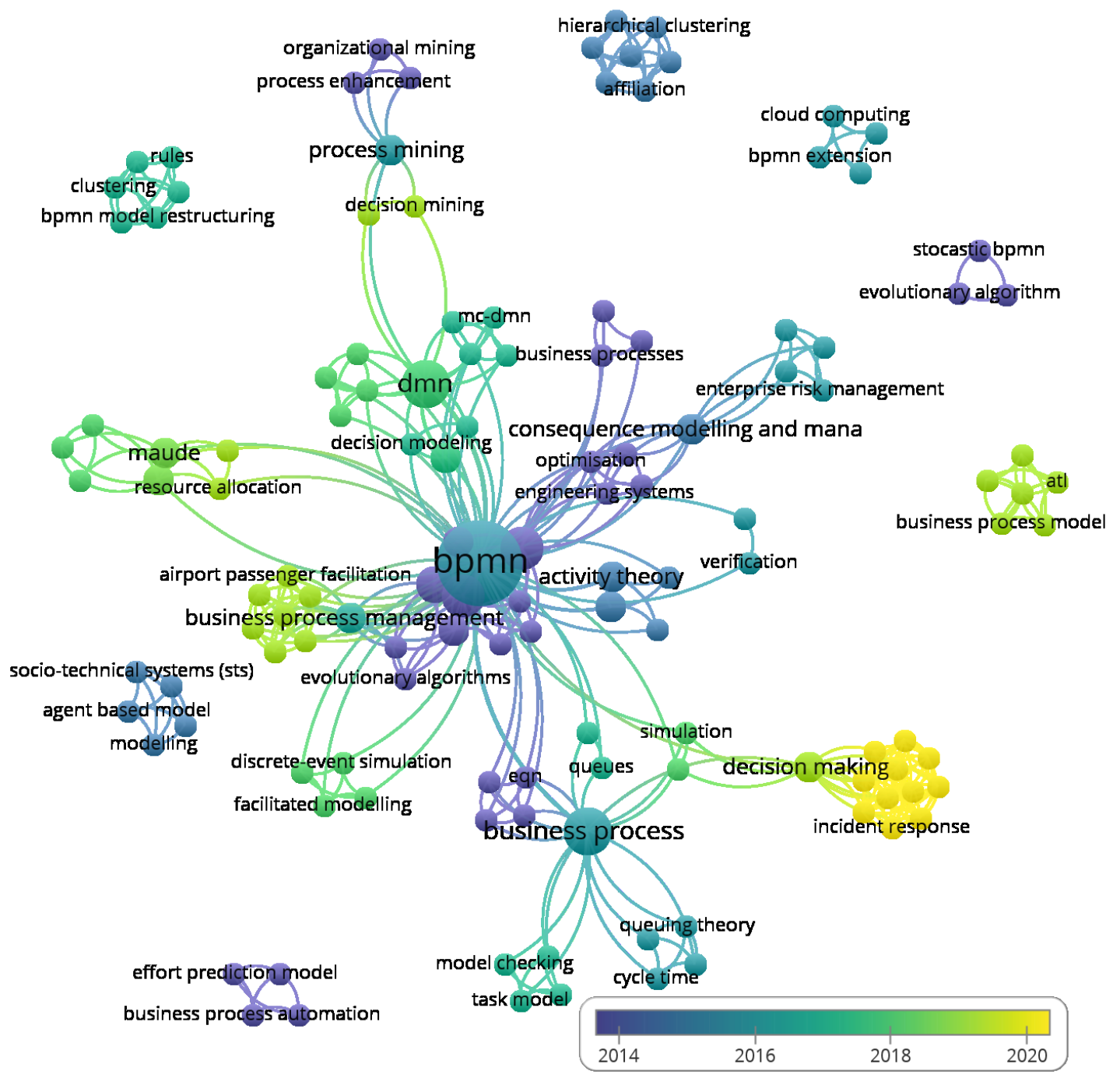

Figure 8. Co-ocurence of Author keywords

A list of all authored keywords with weight link to other keywords is: activity theory (4), affiliation (6), agent based model (4), agent-based systems engineering (3), airport passenger facilitation (8), atl (5), automated verification (4), bayesian network (4), bayesian networks (4), bpm (6), bpmn (60), bpmn business processes (4), bpmn extension (3), bpmn model restructuring (5), business process (18), business process automation (3), business process management (13), business process model (5), business process model measures (3), business process modelling notation (4), business process optimisation (5), business process outsourcing (3), business processes (3), cloud computing (3), clustering (5), communication theory (11), configurable reference model (8), consequence modelling and management (10), contextual factors (8), cycle time (4), decision making (15), decision mining (3), decision model and notation (3), decision modeling (4), decision modelling (5), dikw (11), discrete-event simulation (4), dmn (15), effort prediction model (3), engineering agent-based systems (3), engineering systems (6), enterprise risk management (4), eqn (5), evolutionary algorithm (2), evolutionary algorithms (5), facilitated modelling (4), 
fault tree analysis (6), fault tree generation (6), flow (8), formal risk analysis (6), genetic algorithm (3), healthcare (4), hierarchical clustering (6), incident response (11), integrated modelling (5), interviews (11), jeqn (5), knowledge discovery (6), knowledge management (11), knowledge rediscovery (6), licenses (11), maude (7), mc-dmn (5), mcdm (5), mda (5), metrics (5), model checking (4), model transformations (5), model-driven architecture (4), model-driven engineering (5), modelling (4), object modeling (4), optimisation (6), organizational mining (3), performance (5), performance evaluation (3), petri nets (5), pproduction optimisation (2), preference to criteria (5), prism (8), probability (2), process configuration (8), process enhancement (3), process chain network (5), process merging (8), process mining (6), process modeling (4), process modelling (5), project management (3), qualitative analysis (4), quantitative model checking (10), quantitative service analysis (6), quantitative workflow analysis (4), queues (3), queuing theory (4), reliability analysis and risk assessment methods (4), resource allocation (4), restructuring (6), rewriting logic (7), rules (5), safety assessment software tools (4), safety management and decision making (4), security (11), security operation center (11), sense-making (11), separation of concerns (5), service engineering (6), scheduling (4), simulation (4), simulations (3), social network (5), social network analysis (3), social network model (6), socio-technical systems (sts) (4), soundness (4), space-sensitive process model (8), statistical model checking (4), stocastic bpmn (2), stochastic automata network (3), stochastic bpmn (11), stochastic model checking (13), stochastic modeling and analysis (4), structural and semantic aspects (5), tacit knowledge (11), task analysis (11), task assignment (4), task model (4), timed automata (4), topsis (5), verification (2).

As you can see in the figure, most of the author's keywords are directly or indirectly linked with the term "BPMN." But there are isolated groups. In the following text, we've listed separate keyword groups. We've added a year of publication, a number of citations, and a specific document to which the keywords belong.

- 2013; 2 Citations; (business process automation; business process model measures; effort prediction model; project management) Aysolmaz et al. (2013),

- 2014; 1 Citations; (evolutionary algorithm; pproduction optimisation; stocastic bpmn) Herbert et al. (2014a),

- 2015; 15 Citations; (agent based model; bayesian network; business process modelling notation; modelling; socio-technical systems (sts)) Wu et al. (2015),

- 2015; 1 Citations; (affiliation; bpm; hierarchical clustering; knowledge discovery; knowledge rediscovery; restructuring; social network model) Khlif and Ben-Abdallah (2015),

- 2016; 0 Citations; (bpmn extension; business process outsourcing; cloud computing; genetic algorithm) Rekik et al. (2016),

- 2017; 3 Citations; (bpmn model restructuring; clustering; metrics; rules; social network; structural and semantic aspects) Khlif et al. (2017),

- 2019; 0 Citations; (atl; business process model; model transformations; model-driven engineering; petri nets; process chain network) Gómez-Martínez et al. (2019).

As mentioned above, there are only 46 keywords PLUS (the number of links to other keywords is given in parentheses after the keyword): accuracy (6), ambiguity (6), automation (3), bpmn (20), business process models (6), checking (6), cognitive effectiveness (7), communities (2), complex (0), confidence (6), context (9), critical path (9), decision-making (7), design (7), dimensions (7), distributed simulation (1), framework (8), functional size (2), group creativity (6), identification (9), implementation (5), information (6), integration (2), model (7), neural-network (7), organizational knowledge (1), patterns (6), performance (9), process execution (9), process models (9), productivity (2), quality (2), reality (2), reference models (2), resources (9), risk (6), science research (2), semantics (9), sensemaking (1), simulation (9), strategy (0), systems (6), tables (7), verification (15), web (1), workflow (9).

As can be seen in Figure 9, they are far more separated than the author's keywords. 


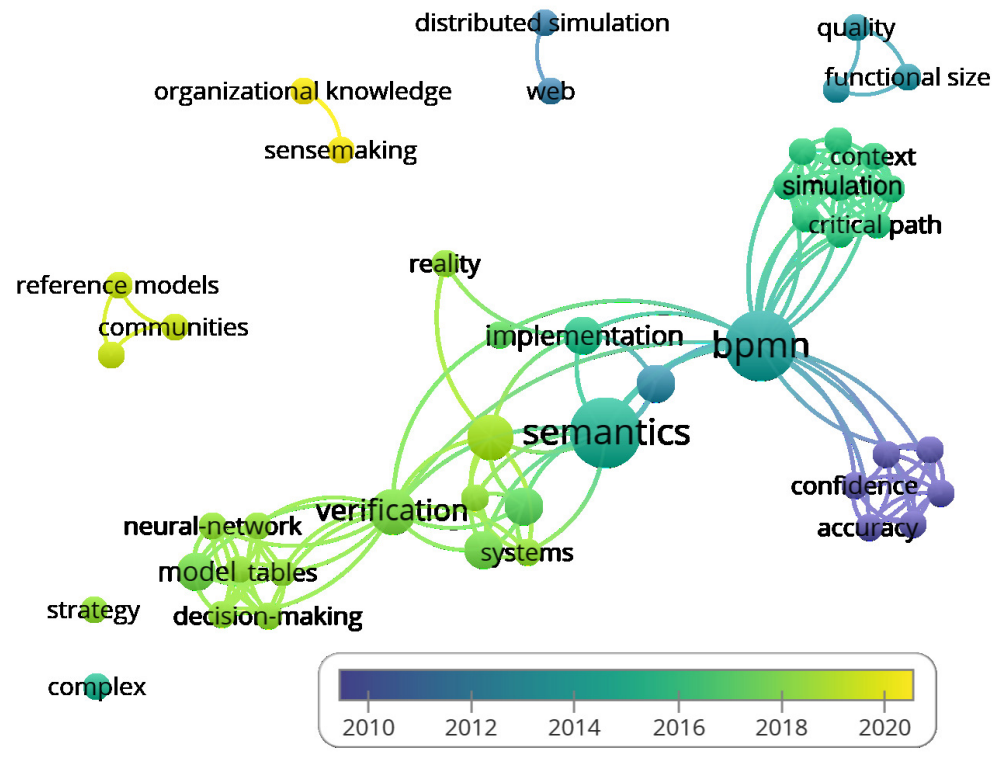

Figure 9. Co-ocurence of KeywordsPlus

\section{Classification of Articles by Methodology}

Based on the expert assessment, we examined the documents on the methods and approaches used. We created seven groups: Probabilistic models, DMN, Dynamics task assignment problem, Evolutionary and genetics algorithms, Queuing theory, social networks and Others, into which we divided the documents. Groups correspond to a method or approach that is an essential part of the publication. These groups are also based on keyword analysis, as some separate groups of copyright keywords belong to highly unique articles. We assigned each document to just one group. That is in contradiction to research areas, where one paper can be attributed to more than one research area. The individual documents and their division between research areas and methodological groups can be seen in table 3 . We further analyzed the documents in terms of time, i.e. the year of publication. As a result, we plotted using the Buble graph (figure 10); when we assigned the publication year to the $\mathrm{X}$-axis, the $\mathrm{Y}$-axis represents methodological groups. The appropriate number of publications corresponding to the given year and the group is indicated in the respective bubble. This quantity is also graphically represented by the size of the given bubble.

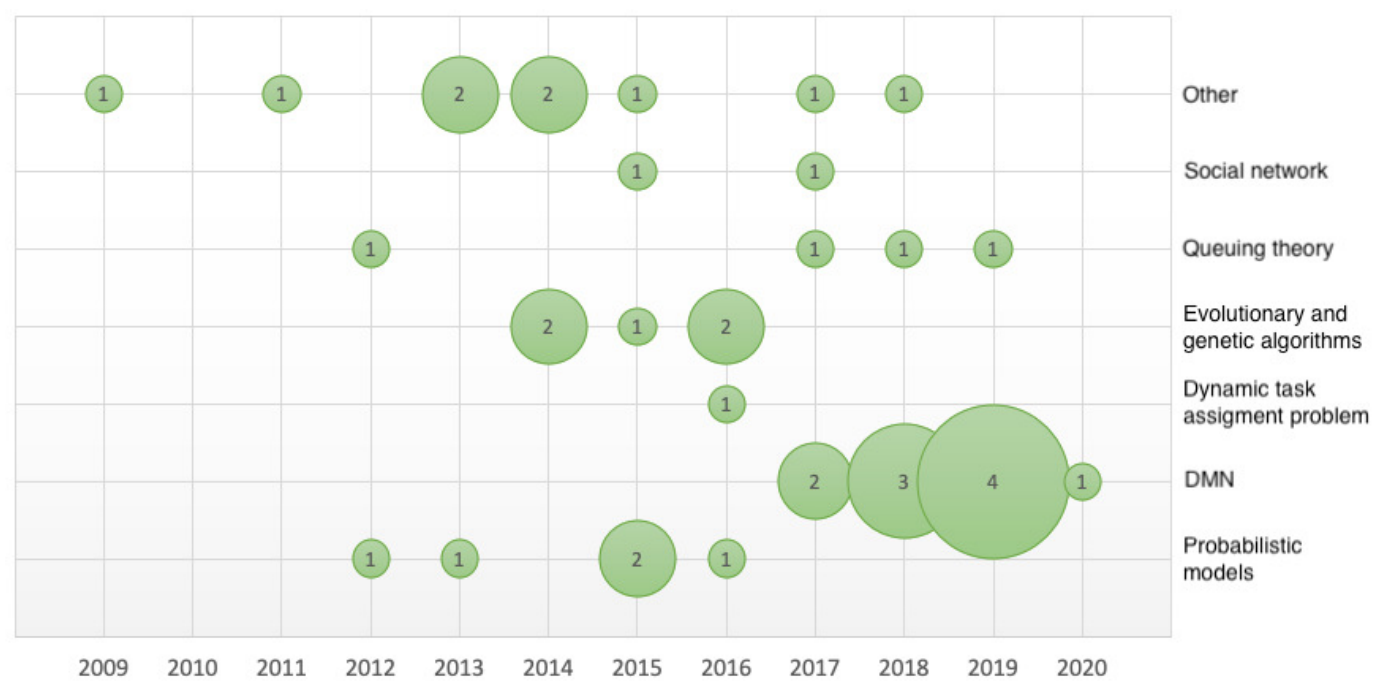

Figure 10. Buble graph - Quantity of papers according to methodological groups and publication year 


\begin{tabular}{|c|c|c|c|c|}
\hline & Computer Science (26) & Engineering(16) & $\begin{array}{l}\text { Operational } \\
\text { Research (6) }\end{array}$ & $\begin{array}{l}\text { Business Eco- } \\
\text { nomics (5) }\end{array}$ \\
\hline $\begin{array}{l}\text { Probabilistic } \\
\text { models (5) }\end{array}$ & $\begin{array}{l}\text { Herbert and Sharp (2012, } \\
\text { 2013); Ceballos et al. } \\
(2015 a, b) \text {; Naoum et al. } \\
(2016)\end{array}$ & $\begin{array}{l}\text { Herbert and Sharp } \\
\text { (2012, 2013); Ce- } \\
\text { ballos et al. (2015a) }\end{array}$ & & \\
\hline DMN (10) & $\begin{array}{l}\text { Batoulis and Weske } \\
\text { (2017); Ghlala et al. } \\
\text { (2017); Hasic et al. } \\
\text { (2018); De Smedt et al. } \\
\text { (2019); Durán et al. } \\
\text { (2019); Suchenia et al. } \\
\text { (2019); Cho et al. (2020) }\end{array}$ & $\begin{array}{l}\text { Figl et al. (2018); } \\
\text { Suchenia et al. } \\
\text { (2019); Cho et al. } \\
(2020)\end{array}$ & $\begin{array}{l}\text { Batoulis } \\
\text { and Weske } \\
(2017) \text {; } \\
\text { Hasic et al. } \\
(2018)\end{array}$ & $\begin{array}{l}\text { Batoulis and } \\
\text { Weske (2017); } \\
\text { Tomaskova } \\
\text { (2018); } \\
\text { Mazhar et al. } \\
\text { (2018) }\end{array}$ \\
\hline $\begin{array}{l}\text { Dynamic task } \\
\text { assignment } \\
\text { problem (1) }\end{array}$ & Xie et al. (2016) & Xie et al. (2016) & & \\
\hline $\begin{array}{l}\text { Evolutionary } \\
\text { and genetic } \\
\text { algorithms (5) }\end{array}$ & $\begin{array}{l}\text { Herbert and Sharp } \\
(2014 b) \text {; Rekik et al. } \\
(2016)\end{array}$ & $\begin{array}{l}\text { Herbert and Sharp } \\
(2014 b) ; \quad \text { Herbert } \\
\text { et al. (2014a, } \\
\text { 2015); Herbert and } \\
\text { Hansen (2016) }\end{array}$ & $\begin{array}{l}\text { Herbert } \\
\text { and Hansen } \\
(2016)\end{array}$ & \\
\hline $\begin{array}{l}\text { Queuing } \\
\text { theory (4) }\end{array}$ & $\begin{array}{l}\text { Bocciarelli and } \\
\text { D'Ambrogio (2012); } \\
\text { Bahaweres et al. (2017); } \\
\text { Gómez-Martínez et al. } \\
\text { (2019) }\end{array}$ & $\begin{array}{l}\text { Bocciarelli and } \\
\text { D'Ambrogio } \\
(2012)\end{array}$ & $\begin{array}{l}\text { Onggo et al. } \\
(2018)\end{array}$ & $\begin{array}{l}\text { Onggo et al. } \\
(2018)\end{array}$ \\
\hline $\begin{array}{l}\text { Social network } \\
\text { (2) }\end{array}$ & $\begin{array}{l}\text { Khlif and Ben-Abdallah } \\
\text { (2015) }\end{array}$ & & & $\begin{array}{l}\text { Khlif et al. } \\
(2017)\end{array}$ \\
\hline Other (9) & $\begin{array}{l}\text { Kamrani et al. (2009); } \\
\text { Braghetto et al. (2011); } \\
\text { Aysolmaz et al. (2013); } \\
\text { Burattin et al. (2013); } \\
\text { Wu et al. (2015); Men- } \\
\text { doza Morales et al. } \\
\text { (2017); Duran et al. } \\
(2018)\end{array}$ & $\begin{array}{l}\text { Kamrani et al. } \\
(2009) ; \quad \text { Burattin } \\
\text { et al. (2013); } \\
\text { Herbert and Sharp } \\
(2014 \mathrm{a}) ; \quad \text { Herbert } \\
\text { et al. (2014b) }\end{array}$ & $\begin{array}{l}\text { Kamrani } \\
\text { et al. (2009); } \\
\text { Wu et al. } \\
(2015)\end{array}$ & \\
\hline
\end{tabular}

Table 3. Documents division into research areas and methodological groups

The largest group consists of publications on DMN and BPMN. There are ten documents. Given the initiate year of DMN, this is the most significant approach serving with BPMN. DMN 1.0 came to the public in September 2015; then the OMG group released DMN 1.1 in June 2016, DMN 1.2 in January 2019 and the latest version of DMN 1.3 was released in March 2020. The latest version did not affect this systematic search. While the growth of publications since 2017, as seen in figure 10, for example, will undoubtedly be affected by the update of the DMN notation.

We assigned only four documents to the methodological group focused on queue theory. That can be seen in table 3, in figure 10, and the specific papers are listed in the following section under the appropriate heading. The largest group is the DMN group with ten documents; we can thus rule out research question R3.

Result: Research question R3 - not confirmed.

In the following section, the particular methods, techniques and approaches and their use in included publications are listed. 


\section{Probabilistic models}

The probabilistic model can be used for decision making when the activity reaches an exclusive splitting gateway and the activity's subject must decide between alternative actions and can be used for predicting or determining between alternative works based on desirable outcomes. Probabilistic models have been presented in the following publications:

- Herbert and Sharp (2012): Quantitative analysis of probabilistic BPMN workflows;

- Herbert and Sharp (2013): Precise quantitative analysis of probabilistic business process model and notation workflows;

- Ceballos et al. (2015a): Towards Probabilistic Decision Making on Human Activities modeled with Business Process Diagrams;

- Ceballos et al. (2015b): A Probabilistic BPMN Normal Form to Model and Advise Human Activities;

- Naoum et al. (2016): A probabilistic method for business process verification: Reachability, Liveness and deadlock detection,

where the (Causal) Bayesian Network or Markov Decision processes were used.

\section{DMN and Decision analysis}

Decision Model and Notation (DMN) is an industry standard for modeling and executing decisions that are determined by business rules. The association of DMN and BPMN is now common practice:

- Batoulis and Weske (2017): Soundness of decision-aware business processes,

- De Smedt et al. (2019): Holistic discovery of decision models from process execution data,

- Durán et al. (2019): A rewriting logic approach to resource allocation analysis in business process models,

- Figl et al. (2018): What we know and what we do not know about DMN,

- Ghlala et al. (2017): MC-DMN: Meeting MCDM with DMN Involving Multi-criteria DecisionMaking in Business Process

- Hasic et al. (2018): Augmenting processes with decision intelligence: Principles for integrated modelling

- Cho et al. (2020): Capturing Tacit Knowledge in Security Operation Centers,

- Mazhar et al. (2018): Designing complex socio-technical process systems - the airport example,

- Suchenia et al. (2019): Towards knowledge interoperability between the UML, DMN, BPMN and CMMN models

- Tomaskova (2018): Modeling Business Processes for Decision-Making.

Both standards fall under OMG.

\section{Dynamic task assignment approach}

The study Xie, Y., Chien, C. F., \& Tang, R. Z. (2016). A dynamic task assignment approach based on individual worklists for minimizing the cycle time of business processes by Xie et al. (2016) develop a dynamic task assignment approach for minimizing the cycle time of business processes. The contribution of this paper lies in developing a dynamic task assignment approach based on queuing theory, individual worklist model, and stochastic theory.

\section{Evolutionary and genetic algorithms}

The evolutionary algorithm is applied in these publications:

- Herbert and Sharp (2014b): Optimisation of BPMN business models via model checking;

- Herbert et al. (2014a): Evolutionary optimization of production materials workflow processes;

- Herbert et al. (2015): Using quantitative stochastic model checking tool to increase safety and improve efficiency in production processes; 
- Herbert and Hansen (2016): Restructuring of workflows to minimise errors via stochastic model checking: An automated evolutionary approach;

to optimize the BP diagram, thus looking for a more efficient process. Especially this publication: Rekik, M., Boukadi, K., \& Ben-Abdallah, H. (2016). Specifying business process outsourcing requirements, Rekik et al. (2016), presented a genetic algorithm to identify most appropriate activities of a business process to be outsourced.

\section{Queuing theory}

In the papers, Bahaweres, R. B., Fitriyah, A., \& Rozy, N. F. (2017). Comparative analysis of business process litigation using queue theory and simulation (case study: Religious courts of South Jakarta) Bahaweres et al. (2017), Onggo, B. S., Proudlove, N. C., D’Ambrogio, S. A., Calabrese, A., Bisogno, S., \& Levialdi Ghiron, N. (2018). A BPMN extension to support discrete-event simulation for healthcare applications: an explicit representation of queues, attributes and data-driven decision points Onggo et al. (2018) and Gomez-Martinez, E; Perez-Blanco, F; de Lara, J; Vara, JM; Marcos, E.(2019).Formal Support of Process Chain Networks using Model-driven Engineering and Petri nets Gómez-Martínez et al. (2019), the authors use queuing theory and simulation to compare processes modeled in BPMN. In the paper, Bocciarelli, P., \& D'Ambrogio, A. (2012). Automated performance analysis of business processes Bocciarelli and D'Ambrogio (2012), authors presented a BP performance model of EQN (Extended Queueing Network) type.

\section{Social network}

The publications below focus on the application of social network analysis metrics (SNA) to studies of biological interaction networks in informatics.

- Khlif and Ben-Abdallah (2015): Semantic and structural performer clustering in BPMN models transformed into social network models;

- Khlif et al. (2017): A methodology for the semantic and structural restructuring of BPMN models.

\section{Other approaches}

The following publications were unique in their approaches. We can mention for example Herbert, L. T., \& Sharp, R. (2014). Workflow fault tree generation through model checking Herbert and Sharp (2014a) with FMEA analysis, Aysolmaz, B., İren, D., \& Demirörs, O. (2013). An effort prediction model based on BPM measures for process automation Aysolmaz et al. (2013) with Linear multiple regression analysis, Braghetto, K. R., Ferreira, J. E., \& Vincent, J. M. (2011). Performance evaluation of business processes through a formal transformation to SAN Braghetto et al. (2011) using Stochastic Automata Network, Kamrani, F., Ayani, R., Moradi, F., \& Holm, G. (2009). Estimating performance of a business process model Kamrani et al. (2009) using a Task assignment approach, Morales, L. E. M., Monsalve, C., \& Villavicencio, M. (2017). Formal verification of business processes as timed automata Mendoza Morales et al. (2017) convert BPMN to Timed Automata and then perform standard Queuing analysis, Burattin, A., Sperduti, A., \& Veluscek, M. (2013). Business models enhancement through discovery of roles Burattin et al. (2013) the authors have extended the process model to roles, specifically designed role-sharing algorithm, Duran, F; Rocha, C; Salaun, G.(2018).Stochastic analysis of BPMN with time in rewriting logic Duran et al. (2018) presents a rewriting logic executable specification of BPMN with time and extended with probabilities, Herbert, LT; Hansen, Z; Jacobsen, P. (2014). SBAT: A STOCHASTIC BPMN ANALYSIS TOOL Herbert et al. (2014b) presents SBAT, a tool framework for the modelling and analysis of complex business workflows and Wu, PPY; Fookes, C; Pitchforth, J; Mengersen, K.(2015) A framework for model integration and holistic modelling of socio-technical systems Wu et al. (2015) presents a layered framework for the purposes of integrating different socio-technical systems (STS) models and perspectives into a whole-of-systems model.

\section{DISCUSSION}

We have identified several gaps and issues for future research. The main gaps concern the research area of business economics. We assumed that this area would be the main and most frequent for the combination of BPMN and OR methods. However, we found that this area could be affected by the absence of specific notation. The relevant publications were created only after the release of version DMN 1.1. The effect of DMN notation will be part of future research. 
An unexpected gap is a solution to finance and human resources management through operational research. We would like to introduce publications Savku and Weber (2018) and Graczyk-Kucharska et al. (2020) as the pioneering works. The first article added the problem of optimal consumption problem from cash flow with delay and regimes. Authors developed the general analytic model setting and methods for the solution by study a stochastic optimal control problem by the tools of the maximum principle. They proved the necessary and sufficient maximum principles for a delayed jump-diffusion with regimes under full and partial information. The second publication focuses on transversal competencies. These competencies are a set of knowledge, skills and attitudes required for different positions and in different professions. The authors used the method of multivariate additive regression spline together with artificial neural networks to create a model describing the influence of various variables on the acceleration of the acquisition of transverse competencies.

We assume that future research will be influenced by simulation and prediction methods. This study showed the use of Agent-based modelling methods and discrete-event simulations, or probabilistic models and social networks, but neural networks or artificial intelligence methods appeared in any publication. Based on this study, we further expect the use of more sophisticated approaches and the effect of new techniques. At the same time, it is possible to extend process modelling to inaccurate data using Fuzzy methods.

\section{CONCLUSION}

The paper presented a systematic overview of publications using the Business Process Model and Notation and operational research methods in process analysis. We analyzed one hundred and twenty-eight selected articles. We chose these articles according to the appropriate strings that we applied to the advanced search in the WOS database. Papers that met the conditions of the study were subjected to various analyzes and briefly described.

The review shows that the processes modelled by BPMN can be extended or analyzed as probabilistic processes, queue theory, or role and task assignments. Alternatively, processes can be optimized using evolutionary or genetic algorithms. Research has also shown the need to identify keywords in publications correctly. For example, only less than two-thirds of the selected articles contained the keyword BPMN, although all documents used this notation. Most of the papers are so-called one-off publications. Only a small number of author teams develop their topic into other continuing publications. Due to that, the average citation is relatively low. Due to the average number of citations to the total number of publications in all research areas, documents falling into the field of operational research are outstanding; there is an average of 7 citations per paper.

We analyzed the publications by research area and found that there is great potential for the research area of business economics (BE), where only a few papers are identified (five in total) but are cited above average. The first document we included in this research area was published in 2017, i.e. only in the last quarter of the examined publication years. The focus of publications on business economics may be affected or caused by the introduction of DMN notation.

Among the authors, smaller collaborating groups around the world have been identified. That groups co-work within the framework of co-authorship and co-citations. We have identified only one single-author publication.

The analysis of keywords showed a significant difference between the keywords assigned by the authors and the so-called PLUS keywords. While the first keywords are almost entirely connectable across publications, Keywords PLUS are significantly diversified.

We have pointed out that the introduction of BPMN 2.0 meant a consequent increase in publishing with this notation.

\section{ACKNOWLEDGMENTS}

The research has been supported by a GACR 18-01246S and by the Faculty of Informatics and Management UHK Specific Research Project.

\section{REFERENCES}

Agatz, N., Erera, A., Savelsbergh, M., and Wang, X. (2012). Optimization for dynamic ride-sharing: A review. European Journal of Operational Research, 223(2):295-303. 
Aguilar-Saven, R. S. (2004). Business process modelling: Review and framework. International Journal of production economics, 90(2):129-149.

Aysolmaz, B., Iren, D., and Demirors, O. (2013). An effort prediction model based on bpm measures for process automation. In Nurcan, S., Proper, H., Soffer, P., Krogstie, J., Schmidt, R., Halpin, T., and Bider, I., editors, Enterprise, Business-Process and Information Systems Modeling, BPMDS 2013, volume 147 of Lecture Notes in Business Information Processing, pages 154-167. 14th International Conference on Business Process Modeling, Development, and Support (BPMDS) / 18th International Conference on Exploring Modeling Methods for Systems Analysis and Design (EMMSAD), CAiSE, Valencia, Spain, Jun 17-18, 2013.

Bacovsky, M., Gavalec, M., and Tomaskova, H. (2013). Inverse fuzzy eigenproblem in databases. In Vojackova, H., editor, Mathematical Methods in Economics 2013, PTS I AND II, pages 13-18. 31st International Conference on Mathematical Methods in Economics, Jihlava, CZECH REPUBLIC, SEP 11-13, 2013.

Bahaweres, R. B., Fitriyah, A., and Rozy, N. F. (2017). Comparative analysis of business process litigation using queue theory and simulation (case study: Religious courts of south jakarta). In 2017 5th International Conference on Cyber and IT Service Management (CITSM 2017), pages 410-416. Denpasar, INDONESIA, AUG 08-10, 2017.

Batoulis, K. and Weske, M. (2017). Soundness of decision-aware business processes. In Carmona, J., Engels, G., and Kumar, A., editors, Business Process Management Forum, volume 297 of Lecture Notes in Business Information Processing, pages 106-124. SIGNAVIO; Celonis; IBM; Diputacio Tarragona; Bizagi; CA Technologies; DCR; Myinvenio. 15th International Conference on Business Process Management (BPM),Barcelona, Spain, Sep 10-15, 2017.

Birge, J. R. and Louveaux, F. (2011). Introduction to stochastic programming. Springer Science \& Business Media.

Bocciarelli, P. and D'Ambrogio, A. (2012). Automated performance analysis of business processes. In Wainer, G., Mosterman, P., DAmbrogio, A., and Zacharewicz, G., editors, Theory of Modeling and Simulation - DEVS Integrative M\&S Symposium 2012 (DEVS 2012), volume 44 of Simulation Series, pages 266-274. Soc Modeling \& Simulat. Theory of Modeling and Simulation - DEVS Integrative M\&S Symposium (DEVS 2012), Orlando, FL, MAR 26-30, 2012.

Braghetto, K. R., Ferreira, J. E., and Vincent, J.-M. (2011). Performance evaluation of business processes through a formal transformation to san. In Thomas, N., editor, Computer Performance Engineering, volume 6977 of Lecture Notes in Computer Science, pages 42+. 8th European Performance Engineering Workshop, EPEW 2011, Borrowdale, UNITED KINGDOM, OCT 12-13, 2011.

Burattin, A., Sperduti, A., and Veluscek, M. (2013). Business models enhancement through discovery of roles. In 2013 IEEE Symposium on Computational Intelligence and Data Mining (CIDM), pages 103-110. IEEE; IEEE Computat Intelligence Soc. IEEE Symposium on Computational Intelligence and Data Mining (CIDM), Singapore, SINGAPORE, APR 16-19, 2013.

Ceballos, H. G., Flores-Solorio, V., and Garcia-Vazquez, J. P. (2015a). Towards probabilistic decision making on human activities modeled with business process diagrams. In Proceedings of the 2015 International Conference on Autonomous Agents \& Multiagent Systems (AAMAS'15), pages 1651-1652. Assoc Comp Machinery; IFAAMAS; NSF; Artificial Intelligence; ACM SIGAI; ARGELA; Microsoft Res; Fundamentals Collect Adapt Sysgt; Japan Soc Software Sci \& Technol; Teknoparkistanbul; Acm In Cooperat. 14th International Conference on Autonomous Agents and Multiagent Systems (AAMAS), Istanbul, TURKEY, MAY 04-08, 2015.

Ceballos, H. G., Flores-Solorio, V., and Pablo Garcia, J. (2015b). A probabilistic bpmn normal form to model and advise human activities. In Baldoni, M., Baresi, L., and Dastani, M., editors, Engineering Multi-Agent Systems, EMAS 2015, volume 9318 of Lecture Notes in Artificial Intelligence, pages 51-69. 3rd International Workshop on Engineering Multi-Agent Systems (EMAS), Turkey, May 05, 2015.

Certo, S. (2003). Influencing initial public offering investors with prestige: Signaling with board structures. Academy of Management Review, 28(3):432-446.

Cheng, Y., Zhao, S., Cheng, B., Chen, X., and Chen, J. (2019). Modeling and deploying iot-aware business process applications in sensor networks. Sensors, 19(1):111.

Chinosi, M. and Trombetta, A. (2012). Bpmn: An introduction to the standard. Computer Standards \& Interfaces, 34(1):124-134.

Cho, S. Y., Happa, J., and Creese, S. (2020). Capturing tacit knowledge in security operation centers. 
IEEE Access, 8:42021-42041.

Cimler, R., Cimr, D., Kuhnova, J., and Tomaskova, H. (2017). Novel effective algorithm for synchronization problem in directed graph. In Nguyen, N., Papadopoulos, G., Jedrzejowicz, P., Trawinski, B., and Vossen, G., editors, Computational Collective Intelligence, ICCCI 2017, PT I, volume 10448 of Lecture Notes in Artificial Intelligence, pages 528-537. Univ Cyprus; Wroclaw Univ Sci \& Technol. 9th International Conference on Computational Collective Intelligence (ICCCI), Nicosia, CYPRUS, SEP 27-29, 2017.

Cimler, R., Tomaskova, H., Kuhnova, J., Dolezal, O., Pscheidl, P., and Kuca, K. (2018). Numeric, agent-based or system dynamics model? which modeling approach is the best for vast population simulation? Current Alzheimer Research, 15(8):789-797.

Cimr, D., Cimler, R., and Tomaskova, H. (2018). Construction of an optimal timetable schedule in accordance with user preferences using the graph coloring algorithm. In Soliman, K., editor, Innovation Management and Education Excellence Through Vision 2020, VOLS I -XI, pages 6940-6946. Int Business Informat Management Assoc. 31st International-Business-Information-ManagementAssociation Conference, Milan, ITALY, APR 25-26, 2018.

Clarivate Analytics (2018). Keywords plus generation, creation, and changes. https: //support.clarivate.com/ScientificandAcademicResearch/s/article/ KeyWords-Plus-generation-creation-and-changes? language=en_US. [Online; accessed 17-July-2020].

Clarivate Analytics (2019). Web of science categories. https://images .webofknowledge. com/images/help/Wos/hp_subject_category_terms_tasca.html. [Online; accessed 7-July-2020].

Cobo, M. J., López-Herrera, A. G., Herrera-Viedma, E., and Herrera, F. (2011). Science mapping software tools: Review, analysis, and cooperative study among tools. Journal of the American Society for information Science and Technology, 62(7):1382-1402.

Dani, V. S., Freitas, C. M. D. S., and Thom, L. H. (2019). Ten years of visualization of business process models: A systematic literature review. Computer Standards \& Interfaces.

Dantzig, G. B. (1998). Linear programming and extensions, volume 48. Princeton university press.

De Ramon Fernandez, A., Ruiz Fernandez, D., and Sabuco Garcia, Y. (2019). Business Process Management for optimizing clinical processes: A systematic literature review. Health Informatics Journal.

De Smedt, J., Hasic, F., vanden Broucke, S. K. L. M., and Vanthienen, J. (2019). Holistic discovery of decision models from process execution data. Knowledge-Based Systems, 183.

Dedrick, J., Gurbaxani, V., and Kraemer, K. (2003). Information technology and economic performance: A critical review of the empirical evidence. ACM Computing Surveys, 35(1):1-28.

Dorfman, R., Samuelson, P. A., and Solow, R. M. (1987). Linear programming and economic analysis. Courier Corporation.

Dubey, S. K. (2010). A review on relation between operation research and different field of sciences. International Journal of Advanced Research in Computer Science, 1(4).

Duran, F., Rocha, C., and Salaun, G. (2018). Stochastic analysis of bpmn with time in rewriting logic. Science of Computer Programming, 168:1-17.

Durán, F., Rocha, C., and Salaün, G. (2019). A rewriting logic approach to resource allocation analysis in business process models. Science of Computer Programming, 183:102303.

Euler, L. (1775). Lettres a une princesse d'allemagne. Letters, 2(102-108):102-108.

Figl, K., Mendling, J., Tokdemir, G., and Vanthienen, J. (2018). What we know and what we do not know about dmn. Enterprise Modelling and Information Systems Architectures-An International Journal, 13.

Garcia, R. (2005). Uses of agent-based modeling in innovation/new product development research. Journal of Product Innovation Management, 22(5):380-398.

Gavalec, M., Mls, K., and Tomaskova, H. (2015). Optimization of the ordinal and cardinal consistency of a preference matrix in decision making. In Alonso, J., Bustince, H., and Reformat, M., editors, Proceedings of the 2015 Conference of the International Fuzzy Systems Association and the European Society for Fuzzy Logic and Technology, volume 89 of Advances in Intelligent Systems Research, pages 851-856. Int Fuzzy Syst Assoc; European Soc Fuzzy Log \& Technol. 16th World Congress of the International-Fuzzy-Systems-Association (IFSA) / 9th Conference of the European-Society-for-FuzzyLogic-and-Technology (EUSFLAT), Gijon, SPAIN, JUN 30-JUL 03, 2015.

Gavalec, M., Plavka, J., and Tomaskova, H. (2014). Interval eigenproblem in max-min algebra. Linear 
Algebra and its Applications, 440:24-33.

Gavalec, M. and Tomaskova, H. (2010). Eigenspace of a circulant max-min matrix. Kybernetika, 46(3, SI):397-404. International Conference on Mathematical Methods in Economy and Industry, Univ S Bohemia, Ceske Budejovice, Czech Republic, JUN 15-18, 2009.

Ghlala, R., Aouina, Z. K., and Ben Said, L. (2017). MC-DMN: Meeting MCDM with DMN Involving Multi-criteria Decision-Making in Business Process. In Gervasi, O and Murgante, B and Misra, S and Borruso, G and Torre, CM and Rocha, AMAC and Taniar, D and Apduhan, BO and Stankova, E and Cuzzocrea, A, editor, Computational Science and its Applications - ICCSA 2017, PT VI, volume 10409 of Lecture Notes in Computer Science, pages 3-16. Univ Trieste; Univ Perugia; Univ Basilicata; Monash Univ; Kyushu Sangyo Univ; Univ Minho. 17th International Conference on Computational Science and its Applications (ICCSA), Trieste, ITALY, JUL 03-06, 2017.

Glassey, O. (2008). A case study on process modelling - three questions and three techniques. Decision Support Systems, 44(4):842-853.

Gómez-Martínez, E., Pérez-Blanco, F., de Lara, J., Vara, J. M., and Marcos, E. (2019). Formal support of process chain networks using model-driven engineering and petri nets. In Proceedings of the 34th ACM/SIGAPP Symposium on Applied Computing, pages 98-100.

Graczyk-Kucharska, M., Özmen, A., Szafrański, M., Weber, G. W., Golińśki, M., and Spychała, M. (2020). Knowledge accelerator by transversal competences and multivariate adaptive regression splines. Central European Journal of Operations Research, 28(2):645-669.

Gu, J., Goetschalckx, M., and McGinnis, L. F. (2010). Research on warehouse design and performance evaluation: A comprehensive review. European Journal of Operational Research, 203(3):539-549.

Hasic, F., De Smedt, J., and Vanthienen, J. (2018). Augmenting processes with decision intelligence: Principles for integrated modelling. Decision Support Systems, 107:1-12.

Herbert, L., Hansen, Z. N. L., and Jacobsen, P. (2015). Using quantitative stochastic model checking tool to increase safety and improve efficiency in production processes. In Nowakowski, T., Mlynczak, M., JodejkoPietruczuk, A., and WerbinskaWojciechowska, S., editors, Safety and Reliability: Methodology and Applications, pages 2405-2416. Wroclaw Univ Technol; Polish Safety \& Reliabil Assoc; European Safety \& Reliabil Assoc. Proceedings of the European Safety and Reliability Conference (ESREL), Wroclaw, POLAND, SEP 14-18, 2014.

Herbert, L., Hansen, Z. N. L., Jacobsen, P., and Cunha, P. (2014a). Evolutionary optimization of production materials workflow processes. In Constantinescu, C., Bauer, W., Sauer, O., and Maropoulos, P., editors, 8TH International Conference on Digital Enterprise Technology - DET 2014 Disruptive Innovation in Manufacturing Engineering Towards the 4th Industrial Revulution, volume 25 of Procedia CIRP, pages 53-60. Int Acad Prod Engn; Fraunhofer Inst Ind Engn IAO. 8th International Conference on Digital Enterprise Technology (DET), Stuttgart, GERMANY, MAR 25-28, 2014.

Herbert, L. and Sharp, R. (2013). Precise quantitative analysis of probabilistic business process model and notation workflows. Journal of Computing and Information Science in Engineering, 13(1).

Herbert, L. and Sharp, R. (2014a). Workflow fault tree generation through model checking. In Steenbergen, R., VanGelder, P., Miraglia, S., and Vrouwenvelder, A., editors, Safety, Reliability and Risk analysis: beyond the horizon, pages 2229-2236. Netherlands Org Appl Sci Res; Delft Univ Technol; Dutch Soc Risk Management \& Reliabil Anal; European Safety \& Reliabil Assoc. 22nd Annual Conference on European Safety and Reliability (ESREL), Amsterdam, Netherlands, SEP 29-OCT 02, 2013.

Herbert, L. T., Hansen, Z., and Jacobsen, P. (2014b). Sbat: A stochastic bpmn analysis tool. In Proceedings of the ASME 12th Biennial Conference on Engineering Systems Design and Analysis - 2014, VOL 3. ASME. 12th ASME Biennial Conference on Engineering Systems Design and Analysis (ESDA2014), Copenhagen, DENMARK, JUN 25-27, 2014.

Herbert, L. T. and Hansen, Z. N. L. (2016). Restructuring of workflows to minimise errors via stochastic model checking: An automated evolutionary approach. Reliability Engineering \& System Safety, 145:351-365. 12th International Association for Probabilistic Safety AssessmentandManagement(PSAM12)Conference, Honolulu, HI, JUN 22-27, 2014.

Herbert, L. T. and Sharp, R. (2012). Quantitative analysis of probabilistic bpmn workflows. In Proceedings of the ASME International Design Engineering Technical Conferences and Computers and Information in Engineering Conference 2012, VOL 2, PTS A and B, pages 509-518. ASME, Design Engn Div; ASME, Comp \& Informat Engn Div. ASME International Design Engineering Technical Conferences/Computers Information in Engineering Conference, Chicago, IL, AUG 12-15, 2012. 
Herbert, L. T. and Sharp, R. (2014b). Optimisation of bpmn business models via model checking. In Proceedings of the ASME International Design Engineering Technical Conferences and Computers and Information in Engineering Conference, 2013, VOL 2B. ASME, Design Engn Div; ASME, Comp $\&$ Informat Engn Div. ASME International Design Engineering Technical Conferences / Computers and Information in Engineering Conference (IDETC/CIE), Portland, OR, AUG 04-07, 2013.

Higgins, J., Lasserson, T., Chandler, J., Tovey, D., and Churchill, R. (2018). Methodological expectations of cochrane intervention reviews. [Cochrane: London, Version 1.06].

Jaafari, A. (1984). Criticism of cpm for project planning analysis. Journal of construction engineering and management, 110(2):222-233.

Kall, P., Wallace, S. W., and Kall, P. (1994). Stochastic programming. Springer.

Kalogirou, S. A. (2003). Artificial intelligence for the modeling and control of combustion processes: a review. Progress in energy and combustion science, 29(6):515-566.

Kamrani, F., Ayani, R., Moradi, F., and Holm, G. (2009). Estimating performance of a business process model. In Proceedings of the 2009 Winter Simulation Confernce (WSC 2009 ), VOL 1-4, Winter Simulation Conference Proceedings, pages 2828+. IEEE. Winter Simulation Conference 2009, Austin, TX, DEC 13-16, 2009.

Khlif, W. and Ben-Abdallah, H. (2015). Semantic and structural performer clustering in bpmn models transformed into social network models. In Lorenz, P. and Maciaszek, L., editors, 2015 10TH International Joint Conference on Software Technologies (ICSOFT), VOL 1, pages 79-86. Inst Syst \& Technologies Informat Control \& Commun; Univ Haute Alsace; IEICE Special Interest Grp Software Interprise Modelling; IEEE Comp Soc Tech Council Software Engn; SCITEVENTS; SCITEPRESS; Univ Upper Alsace; Univ Haute Alsace; IEEE Comp Soc; TCSE. 10th International Conference on Software Technologies (ICSOFT), Colmar, FRANCE, JUL 20-22, 2015.

Khlif, W., Ben-Abdallah, H., and Ben Ayed, N. E. (2017). A methodology for the semantic and structural restructuring of bpmn models. Business Process Management Journal, 23(1):16-46.

Kitchenham, B. and Charters, S. (2007). Guidelines for performing systematic literature reviews in software engineering. Technical report, pages 1-57.

Kocbek, M., Jost, G., Hericko, M., and Polancic, G. (2015). Business process model and notation: The current state of affairs. Computer Science and Information Systems, 12(2):509-539.

Kopecky, M. and Tomaskova, H. (2019). Activity based costing and process simulations. In Jedlicka, P., Maresova, P., and Soukal, I., editors, Hradec Economic Days, Vol. 9, Issue I, Hradec Economic Days, pages 431-438. Univ Hradec Kralove, Fac Informat \& Management; Wroclaw Univ Econ; Cracow Univ Econ; Univ S Bohemia, Off Transfer Technologies; Czech Natl Bank. 17th International Scientific Conference on Hradec Economic Days, Hradec Kralove, Czech Republic, FEB 05-06, 2019.

Kopecky, M. and Tomaskova, H. (2020). The business process model and notation used for the representation of alzheimer's disease patients care process. Data, 5(1):16.

Kozlowski, S. W. J., Chao, G. T., Grand, J. A., Braun, M. T., and Kuljanin, G. (2013). Advancing multilevel research design: Capturing the dynamics of emergence. Organizational Research Methods, 16(4):581-615.

Krenek, J., Kuca, K., Krejcar, O., Maresova, P., Sobeslav, V., and Blazek, P. (2014). Artificial neural network tools for computerised data modeling and processing. In 2014 IEEE 15th International Symposium on Computational Intelligence and Informatics (CINTI), International Symposium on Computational Intelligence and Informatics, pages 255-260. IEEE Hungary Sect; IEEE Computat Intelligence Chapter; IEEE Joint Chapter Robot Automat \& Ind Elect Soc; IEEE SMC Soc; Obuda Univ; Hungarian Fuzzy Ass. Budapest, BAHRAIN, NOV 19-21, 2014.

Krogstie, J., Sindre, G., and Jorgensen, H. (2006). Process models representing knowledge for action: a revised quality framework. European Journal of Information Systems, 15(1):91-102. Conference on Action in Language, Organisations and Information Systems, Limerick, IRELAND, MAR 15-16, 2005.

Lane, M. S., Mansour, A. H., and Harpell, J. L. (1993). Operations research techniques: A longitudinal update 1973-1988. Interfaces, 23(2):63-68.

Maltz, E. and Kohli, A. (1996). Market intelligence dissemination across functional boundaries. Journal of Marketing Research, 33(1):47-61.

Maresova, P. (2010). Knowledge management in czech enterprises. E \& M Ekonomie a Management, 13(1):131-144.

Maresova, P., Sobeslav, V., and Krejcar, O. (2017). Cost-benefit analysis - evaluation model of cloud 
computing deployment for use in companies. Applied Economics, 49(6):521-533.

Maresova, P., Tomaskova, H., and Kuca, K. (2016). The use of simulation modelling in the analysis of the economic aspects of diseases in old age. In Bilgin, M., Danis, H., Demir, E., and Can, U., editors, Business Chammenges in the Changing Economic Landscape, VOL. 1, pages 369-377. Eurasia Business \& Econ Soc. 14th Conference of the Eurasia-Business-and-Economics-Society (EBES), Barcelona, SPAIN, OCT 23-25, 2014.

Mazhar, S., Wu, P. P.-Y., and Rosemann, M. (2018). Designing complex socio-technical process systemsthe airport example. Business Process Management Journal.

Melao, N. and Pidd, M. (2000). A conceptual framework for understanding business processes and business process modelling. Information Systems Journal, 10(2):105-129.

Mendoza Morales, L. E., Monsalve, C., and Villavicencio, M. (2017). Formal verification of business processes as timed automata. In 2017 12TH Iberian Conference on Information Systems and Technologies (CISTI), Iberian Conference on Information Systems and Technologies. Assoc Iberica Sistemas Tecnologias Informaco; Inst Univ Lisboa; Asoc Tecnicos Informatica; Assoc Portuguesa Empreendedorismo; IEEE SMC; IEEE Portugal Sect; FCA; Lidel; SAS; Silabo; TAP. Lisbon, PORTUGAL, JUN 21-24, 2017.

Moher, D., Liberati, A., Tetzlaff, J., Altman, D. G., and Group, T. P. (2009). Preferred reporting items for systematic reviews and meta-analyses: The prisma statement. PLOS Medicine, 6(7):1-6.

Mryglod, O., Kenna, R., Holovatch, Y., and Berche, B. (2013). Comparison of a citation-based indicator and peer review for absolute and specific measures of research-group excellence. Scientometrics, 97(3):767-777.

Naoum, M., El Hichami, O., Al Achhab, M., and El Mohajir, B. e. (2016). A probabilistic method for business process verification: Reachability, liveness and deadlock detection. In ElMohajir, M., Chahhou, M., AlAchhab, M., and ElMohajir, B., editors, 2016 4TH IEEE International Colloquium on Information Science and Technology (CIST), Colloquium in Information Science and Technology, pages 128-132. IEEE; IEEE Comp Soc; IEEE Commun Soc; INNOV ORG; ENSIAS; QATAR UNIV; Akhawayn Univ; Technische Univ Munchen; INSA ROUEN; IEEE Morocco Sect; IEEE Morocco Comp \& Commun Joint Chapter. Tangier, MOROCCO, OCT 24-26, 2016.

Negahban, A. and Smith, J. S. (2014). Simulation for manufacturing system design and operation: Literature review and analysis. Journal of Manufacturing Systems, 33(2):241-261.

Nisler, J. and Tomaskova, H. (2017). Bpmn as a quality tool for the efficient functioning of the company. In Soliman, K., editor, Vision 2020: Sustainable Economic Development, Innovation Management, and Global Growth, VOLS I-IX, 2017, pages 3257-3263. Business Inform Management Assoc. 30th International Business-Information-Management-Association Conference, Spain, Nov 08-09, 2017.

Nutt, P. C. (1983). Implementation approaches for project planning. Academy of Management Review, 8(4):600-611.

OMG - The Object Management Group (2011). The business process model and notation specification. http://www.omg.org/spec/BPMN/2.0/. [Online; accessed 30-OCtober-2018].

OMG.org (2018). History of formal versions. https://www.omg.org/spec/BPMN. [Online; accessed 20-November-2018].

Onggo, B. S. S., Proudlove, N. C., D’Ambrogio, S. A., Calabrese, A., Bisogno, S., and Ghiron, N. L. (2018). A bpmn extension to support discrete-event simulation for healthcare applications: an explicit representation of queues, attributes and data-driven decision points. Journal of the Operational Research Society, 69(5):788-802.

Oudah, M., Jabeen, F., and Dixon, C. (2018). Determinants linked to family business sustainability in the uae: An ahp approach. Sustainability, 10(1):246.

Pellerin, R., Perrier, N., and Berthaut, F. (2020). A survey of hybrid metaheuristics for the resourceconstrained project scheduling problem. European Journal of Operational Research, 280(2):395-416.

Recker, J. (2012). Bpmn research: what we know and what we don't know. In International Workshop on Business Process Modeling Notation, pages 1-7. Springer.

Recker, J., Rosemann, M., Indulska, M., and Green, P. (2009). Business process modeling-a comparative analysis. Journal of the association for information systems, 10(4):1.

Rekik, M., Boukadi, K., and Ben-Abdallah, H. (2016). Specifying business process outsourcing requirements. In Lorenz, P., Cardoso, J., Maciaszek, L., and VanSinderen, M., editors, Software Technologies (ICSOFT 2015), volume 586 of Communications in Computer and Information Science, pages 175-190. 
Inst Syst \& Technologies Informat Control \& Commun; Univ Haute Alsace; IEICE Special Interest Grp Software Interprise Modelling; IEEE Comp Soc Tech Council Software Engn. 10th International Conference on Software Technologies (ICSOFT), Colmar, FRANCE, JUL 20-22, 2015.

Repenning, N. (2002). A simulation-based approach to understanding the dynamics of innovation implementation. Organization Science, 13(2):109-127.

Sadiq, W. and Orlowska, M. (2000). Analyzing process models using graph reduction techniques. Information Systems, 25(2):117-134. 11th International Conference on Advanced Information Systems Engineering (CAiSE 99), HEIDELBERG, GERMANY, JUN 14-18, 1999.

Sarac, A., Absi, N., and Dauzère-Pérès, S. (2010). A literature review on the impact of rfid technologies on supply chain management. International journal of production economics, 128(1):77-95.

Savku, E. and Weber, G.-W. (2018). A stochastic maximum principle for a markov regime-switching jump-diffusion model with delay and an application to finance. Journal of Optimization Theory and Applications, 179(2):696-721.

Schrijver, A. (1998). Theory of linear and integer programming. John Wiley \& Sons.

Shane, S. and Cable, D. (2002). Network ties, reputation, and the financing of new ventures. Management Science, 48(3):364-381.

Shannon, R. E., Long, S. S., and Buckles, B. P. (1980). Operation research methodologies in industrial engineering: A survey. A I I E Transactions, 12(4):364-367.

Shapiro, A., Dentcheva, D., and Ruszczyński, A. (2014). Lectures on stochastic programming: modeling and theory. SIAM.

Silver, B. (2009). Bpmn method and style: A levels-based methodology for bpm process modeling and improvement using bpmn 2.0. Cody-Cassidy Press, US.

Sterman, J. (1994). Learning in and about complex-systems. System Dynamics Review, 10(2-3):291-330.

Subramanian, N. and Ramanathan, R. (2012). A review of applications of analytic hierarchy process in operations management. International Journal of Production Economics, 138(2):215-241.

Suchenia, A., Kluza, K., Wisniewski, P., Jobczyk, K., and Ligeza, A. (2019). Towards knowledge interoperability between the uml, dmn, bpmn and cmmn models. In MATEC Web of Conferences, volume 252, page 02011. EDP Sciences.

Tomaskova, H. (2009). Marketing research of mobile technology used by firms like advantage. In Perlovsky, L., Dionysiou, D., Zadeh, L., Kostic, M., GonzalezConcepcion, C., and Jaberg, H., editors, AEBD '09: Proceedings of the World Multiconference on Applied Economics, Business and Development, Recent Advances in Computer Engineering, pages 202-205. Spain, Jul 01, 2009.

Tomaskova, H. (2017). Levels of business process modeling. In Soliman, K., editor, Vision 2020: Sustainable Economic Development, Innovation Management, and Global Growth, Vols I-IX, 2017, pages 3495-3498. Business Inform Management Assoc. 30th International Business-InformationManagement-Association Conference, Madrid, Spain, Nov 08-09, 2017.

Tomaskova, H. (2018). Modeling business processes for decision-making. In Soliman, K., editor, Innovation Management and Education Excellence Through Vision 2020, 2018, VOLS I-XI, pages 4318-4321. Int Business Informat Management Assoc. 31st International-Business-InformationManagement-Association Conference, Milan, ITALY, APR 25-26, 2018.

Tomaskova, H. and Gavalec, M. (2013). Decision making based on tropical algebra. In Vojackova, H., editor, Mathematical Methods in Economics 2013, PTS I AND II, pages 950-955. 31st International Conference on Mathematical Methods in Economics, Jihlava, CZECH REPUBLIC, SEP 11-13, 2013.

Tomaskova, H. and Gavalec, M. (2014). Max-prod eigenvectors and their applications in decision making. In Talasova, J., Stoklasa, J., and Talasek, T., editors, Mathematical Methods in Economics (MME 2014), pages 1045-1050. 32nd International Conference on Mathematical Methods in Economics (MME), Olomouc, CZECH REPUBLIC, SEP 10-12, 2014.

Tomaskova, H., Kopecky, M., and Maresova, P. (2019a). Process cost management of alzheimer's disease. Processes, 7(9):582.

Tomaskova, H., Kuhnova, J., Cimler, R., Dolezal, O., and Kuca, K. (2016). Prediction of population with alzheimer's disease in the european union using a system dynamics model. Neuropsychiatric Disease and Treatment, 12:1589-1598.

Tomaskova, H., Kuhnova, J., and Kuca, K. (2015). Economic model of alzheimer's disease. In Soliman, K., editor, Innovation Vision 2020: from Regional Development Sustainability to Global Economic Growth, VOL I-VI, pages 3120+. 25th International-Business-Information-Management-Association 
Conference, Amsterdam, Netherlands, May 07-08, 2015.

Tomaskova, H., Maresova, P., Penhaker, M., Augustynek, M., Klimova, B., Fadeyi, O., and Kuca, K. (2019b). The business process model and notation of open innovation: The process of developing medical instrument. Journal of Open Innovation: Technology, Market, and Complexity, 5(4):101.

Tsakalidis, G., Vergidis, K., Kougka, G., and Gounaris, A. (2019). Eligibility of bpmn models for business process redesign. Information, 10(7).

Van der Aalst, W., Adriansyah, A., and van Dongen, B. (2012). Replaying history on process models for conformance checking and performance analysis. Wiley Interdisciplinary Reviews: Data Mining and Knowledge Discovery, 2(2):182-192.

van der Aalst, W. M. P., Reijers, H. A., Weijters, A. J. M. M., van Dongen, B. F., de Medeiros, A. K. A., Song, M., and Verbeek, H. M. W. (2007). Business process mining: An industrial application. Information Systems, 32(5):713-732.

Van Eck, N. J., Waltman, L., Dekker, R., and van den Berg, J. (2010). A comparison of two techniques for bibliometric mapping: Multidimensional scaling and vos. Journal of the American Society for Information Science and Technology, 61(12):2405-2416.

Velasquez, M. and Hester, P. T. (2013). An analysis of multi-criteria decision making methods. International journal of operations research, 10(2):56-66.

Venn, J. (1880). I. on the diagrammatic and mechanical representation of propositions and reasonings. The London, Edinburgh, and Dublin philosophical magazine and journal of science, 10(59):1-18.

White, S. A. (2008). BPMN modeling and reference guide: understanding and using BPMN. Future Strategies Inc.

Wu, P. P.-Y., Fookes, C., Pitchforth, J., and Mengersen, K. (2015). A framework for model integration and holistic modelling of socio-technical systems. Decision Support Systems, 71:14-27.

Xie, Y., Chien, C.-F., and Tang, R.-Z. (2016). A dynamic task assignment approach based on individual worklists for minimizing the cycle time of business processes. Computers \& Industrial Engineering, 99:401-414.

Xu, X., Wang, L., and Newman, S. T. (2011). Computer-aided process planning-a critical review of recent developments and future trends. International Journal of Computer Integrated Manufacturing, 24(1):1-31.

Zarour, K., Benmerzoug, D., Guermouche, N., and Drira, K. (2019). A systematic literature review on bpmn extensions. Business Process Management Journal.

Zyoud, S. H. and Fuchs-Hanusch, D. (2017). A bibliometric-based survey on ahp and topsis techniques. Expert systems with applications, 78:158-181. 